\title{
QUÍMICA FORENSE: PERSPECTIVAS SOBRE NOVOS MÉTODOS ANALÍTICOS APLICADOS À DOCUMENTOSCOPIA, BALÍSTICA E DROGAS DE ABUSO
}

\author{
Wanderson Romão, Nicolas V. Schwab e Maria Izabel M. S. Bueno* \\ Departamento de Química Analítica, Instituto de Química, Universidade Estadual de Campinas, \\ CP 6154, 13083-970 Campinas - SP, Brasil \\ Regina Sparrapan e Marcos N. Eberlin \\ Departamento de Química Orgânica, Instituto de Química, Universidade Estadual de Campinas, \\ CP 6154, 13083-970 Campinas - SP, Brasil

\section{Andrea Martiny} \\ Instituto Nacional de Metrologia, Normalização e Qualidade Industrial, Av. N. Sra. das Graças, 50, \\ 25250-020 Duque de Caxias - RJ, Brasil
}

\section{Bruno D. Sabino}

Instituto Nacional de Metrologia, Normalização e Qualidade Industrial, Av. N. Sra. das Graças, 50, 25250-020 Duque de Caxias - RJ / Instituto de Criminalística Carlos Éboli, R. Pedro I, 28, 20060-050 Rio de Janeiro - RJ, Brasil Adriano O. Maldaner

Polícia Federal Brasileira, Ministério da Justiça, Instituto Nacional de Criminalística, 70610-200 Brasília - DF, Brasil

Recebido em 3/11/10; aceito em 14/4/11; publicado na web em 12/7/11

\begin{abstract}
FORENSIC CHEMISTRY: PERSPECTIVE OF NEW ANALYTICAL METHODS APPLIED TO DOCUMENTOSCOPY, BALLISTIC AND DRUGS OF ABUSE. In this review recent methods developed and applied to solve criminal occurences related to documentoscopy, ballistic and drugs of abuse are discussed. In documentoscopy, aging of ink writings, the sequence of line crossings and counterfeiting of documents are aspects to be solved with reproducible, fast and non-destructive methods. In ballistic, the industries are currently producing "lead-free" or "nontoxic" handgun ammunitions, so new methods of gunshot residues characterization are being presented. For drugs analysis, easy ambient sonic-spray ionization mass spectrometry (EASI-MS) is shown to provide a relatively simple and selective screening tool to distinguish $m$-CPP and amphetamines (MDMA) tablets, cocaine and LSD.
\end{abstract}

Keywords: documentoscopy; ballistic; drugs of abuse.

\section{INTRODUÇÃOO}

A química forense é o ramo das ciências forenses voltado para a produção de provas materiais para a justiça, através da análise de substâncias diversas em matrizes, tais como drogas lícitas e ilícitas, venenos, acelerantes e resíduos de incêndio, explosivos, resíduos de disparo de armas de fogo, combustíveis, tintas e fibras. Embora a química forense seja um tema muito importante e que desperte cada vez mais interesse perante a sociedade científica, a sua aplicação no campo da criminalística ainda constitui uma nova linha de pesquisa no Brasil. A Figura 1 mostra a distribuição dos recentes métodos analíticos que estão sendo aplicados em documentoscopia, balística forense e drogas de abuso, nos períodos de (1a) 1990-2000 e (1b-c) 2001-2010.

$\mathrm{Na}$ documentoscopia, até 2000, as técnicas de espectroscopia molecular (infravermelho, ${ }^{1-4}$ Raman,,${ }^{5,6}$ fluorescência molecular ${ }^{7}$ ) e de separação (cromatografia ${ }^{8-10}$ e eletroforese ${ }^{11-15}$ ) foram as mais empregadas, apresentando juntas, 219 citações (Figura 1a). A partir de 2001, com o surgimento de novas técnicas em espectrometria de massas (MS - mass spectrometry), problemas complexos que existiam até o momento tornaram-se solucionáveis. Entre eles, podem-se destacar:

*e-mail: bell@iqm.unicamp.br cruzamento de traços, falsificação de documentos e datação de tintas. Estas análises podem ser realizadas de maneira rápida, sensível e sem qualquer preparação de amostra. Essa evolução na área de MS se deve principalmente ao surgimento de novos sistemas de ionização, como EASI (easy ambient sonic-spray ionization), DESI (desorption electrospray ionization) e DART (direct analysis in real time). ${ }^{16-24}$ A partir de 2005, vários trabalhos começaram a ser publicados (13 publicações e 151 citações, respectivamente) sendo, atualmente, a EASI uma das técnicas usadas pela Polícia Federal Brasileira na investigação da autenticidade de documentos questionados.

Análises da área de balística forense também têm se beneficiado pelos avanços da Química. Por exemplo, no momento em que uma arma de fogo é disparada, uma grande quantidade de material na fase gasosa ou aerosol sólido é produzida e expelida juntamente com o projétil. Parte desse material se solidifica na forma de material particulado pelo choque térmico, formando o que é conhecido como resíduo de tiro ou GSR (gunshot residues). Os resíduos de tiro são compostos especialmente por elementos derivados da deflagração da espoleta (chumbo, bário e antimônio, $\mathrm{Pb} / \mathrm{Ba} / \mathrm{Sb}$ ), além de pólvora parcialmente fundida, elementos do cano e do próprio projétil, que se depositam no atirador (especialmente nas mãos, rosto e roupas), em pessoas próximas e mesmo na vítima. A presença dos GSR na vítima normalmente está restrita a regiões próximas ao orifício de 

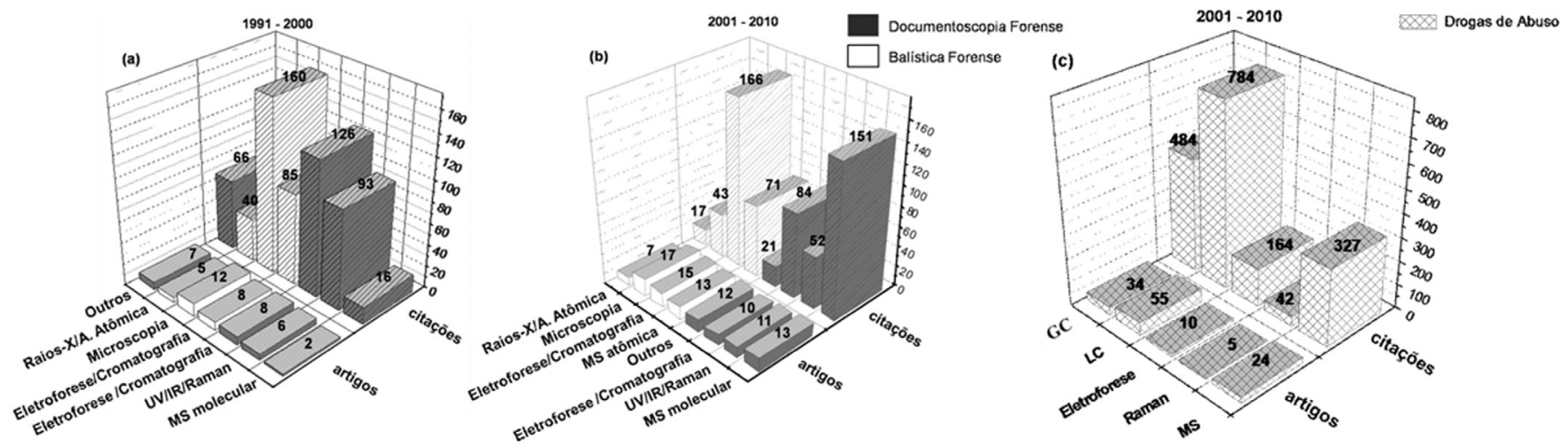

Figura 1. Distribuição dos recentes métodos analíticos aplicados em documentoscopia, balística forense e drogas de abuso, nos períodos de (a) 1990-2000 e (b-c) 2001-2010. Pesquisa realizada em 8/4/2010, usando a fonte de dados da web of science: (keywords = gunshot residues and forensic; document analysis and forensic; cocaine, ecstasy, LSD, marijuana and cannabis analysis and forensic)

entrada, embora em disparos a curta distância, possam se depositar em outras regiões. A detecção desses resíduos pode colocar o suspeito no local de crime.

A identificação dos elementos $\mathrm{Pb} / \mathrm{Ba} / \mathrm{Sb}$, simultaneamente, em uma partícula de morfologia esférica, é a única prova inquestionável de que uma pessoa pode ter produzido um tiro, ou ter estado ao lado de quem produziu, ou ainda, ter manuseado uma arma de fogo. Atualmente, a análise dos GSR inorgânicos (análise morfológica de partículas contendo simultâneamente $\mathrm{Pb} / \mathrm{Sb} / \mathrm{Ba}$ ) é feita por microscopia eletrônica de varredura com detector de energia de dispersão de raios $\mathrm{X}$ (SEM/EDX), justificando o grande número de trabalhos existentes, (Figuras 1a-b). ${ }^{25-30}$

Em 1998, a Companhia Brasileira de Cartuchos (CBC) lançou no mercado internacional uma munição denominada CleanRange ${ }^{\circledast}$, uma completa inovação em relação às munições anteriormente produzidas. Além de não apresentar metais pesados na composição da espoleta, os projéteis são encamisados totalmente para evitar a evaporação de $\mathrm{Pb}$ oriundo do núcleo do projetil. A utilização dessa munição em especial tem se mostrado extremamente problemática de ser evidenciada pelos GSR inorgânicos, mesmo utilizando SEM/ EDX. ${ }^{31}$ Dessa forma, pesquisadores têm utilizado novas metodologias para a caracterização dos resíduos orgânicos (pólvora) e inorgânicos (Figura 1b), ${ }^{32}$ utilizando técnicas de separação como eletroforese ${ }^{13,33}$ e cromatografia líquida ${ }^{34}$ ou espectrometria atômica (fluorescência de raios-X, XRF, ${ }^{35-37}$ além da espectrometria de massas com plasma indutivamente acoplado, ICP-MS, ${ }^{38,39}$ espectrometria de massas de íons secundários ${ }^{40}$ e espectrometria de absorção atômica). ${ }^{41}$

A análise de drogas de abuso é uma das áreas que desperta grande interesse da comunidade científica no que tange à química forense. $\mathrm{O}$ combate ao narcotráfico e o aumento de dependentes químicos são grandes desafios que a humanidade enfrenta diariamente. A química forense, além de identificar os principais componentes que constituem uma amostra de droga e caracterizá-la como ilícita, pode ser utilizada na identificação de compostos químicos remanescentes do processo de refino ou fabricação, fornecendo perfis químicos e elementos que correlacionam amostras de diferentes apreensões, identificando rotas e origens geográficas de produção. ${ }^{42}$ Técnicas que exigem pouca, ou mesmo nenhuma, preparação de amostras vêm sendo aplicadas com esse propósito, permitindo resultados rápidos, seguros e reprodutíveis (Figura 1c, técnica de MS). A EASI-MS (easy ambient sonic-spray ionization mass spectrometry), por exemplo, permite detectar ingredientes ativos e excipientes orgânicos diretamente a partir da superfície de um comprimido de ecstasy, ou mesmo fornecer resultados mais robustos na análise de placas cromatográficas de camada delgada (TLC), normalmente empregadas em rotinas de Perícia Forense.
Neste artigo de revisão, são mostradas as principais metodologias atuais desenvolvidas em documentoscopia, balística forense e drogas de abuso. Na área de documentoscopia, são enfatizadas as técnicas de espectrometria no infravermelho, espectrometria Raman e espectrometria de massas; na balística, fluorescência de raios-X e eletroforese; e na área de drogas de abuso, a EASI-MS.

\section{DOCUMENTOSCOPIA}

A documentoscopia é a parte da criminalística que estuda a autenticidade de documentos e, em caso contrário, determina a sua autoria. Ela se distingue de outras disciplinas, que também se preocupam com os documentos, porque tem um cunho nitidamente policial: não se satisfaz com a prova da ilegitimidade do documento, mas procura determinar quem foi o seu autor e os meios empregados para sua produção, o que não ocorre com outras. Atualmente, as metodologias desenvolvidas são destinadas principalmente a problemas como análise e datação de tintas, falsificação de documentos e cruzamento de traços. ${ }^{43}$ No Brasil, o papel-moeda é sem dúvida o principal exemplo de falsificação.

\section{Microespectroscopia na região do infravermelho por transformada de Fourier}

No início da década de 1990, sistemas espectroscópicos de imagem química tornaram possível a aquisição de espectros e informações espaciais simultaneamente, a chamada espectroscopia de imagem. A obtenção de espectros com alta resolução espacial identifica espécies químicas na amostra e seu mapa de distribuição. A espectroscopia de imagem essencialmente combina espectroscopia vibracional e imagem digital. Ela se baseia na medida de um espectro completo por unidade da superfície da amostra (pixel). ${ }^{44,45}$

Em 2008, Bojko e colaboradores ${ }^{2}$ examinaram interseções de linhas homogêneas e heterogêneas (cruzamento de linhas de mesma ou diferentes composições químicas, respectivamente), escritas e impressas sobre o papel. Quatro canetas esferográficas, duas impressoras a laser e ink-jet foram analisadas, respectivamente. Uma área de aproximadamente $2 \times 2 \mathrm{~cm}$ do papel, correspondendo ao cruzamento das linhas, foi utilizada para a construção da imagem. O método foi otimizado para aquisição das imagens no modo reflectância total atenuada (ATR), usando como porta-amostra um cristal de seleneto de zinco $(\mathrm{ZnSe})$. Os resultados obtidos pelos autores são apenas conclusivos para a análise de interseção de linhas heterogêneas (linha produzida pela impressora a laser sobre caneta esferográfica), Figura 2a. Utilizando frequências características de uma determinada linha, 

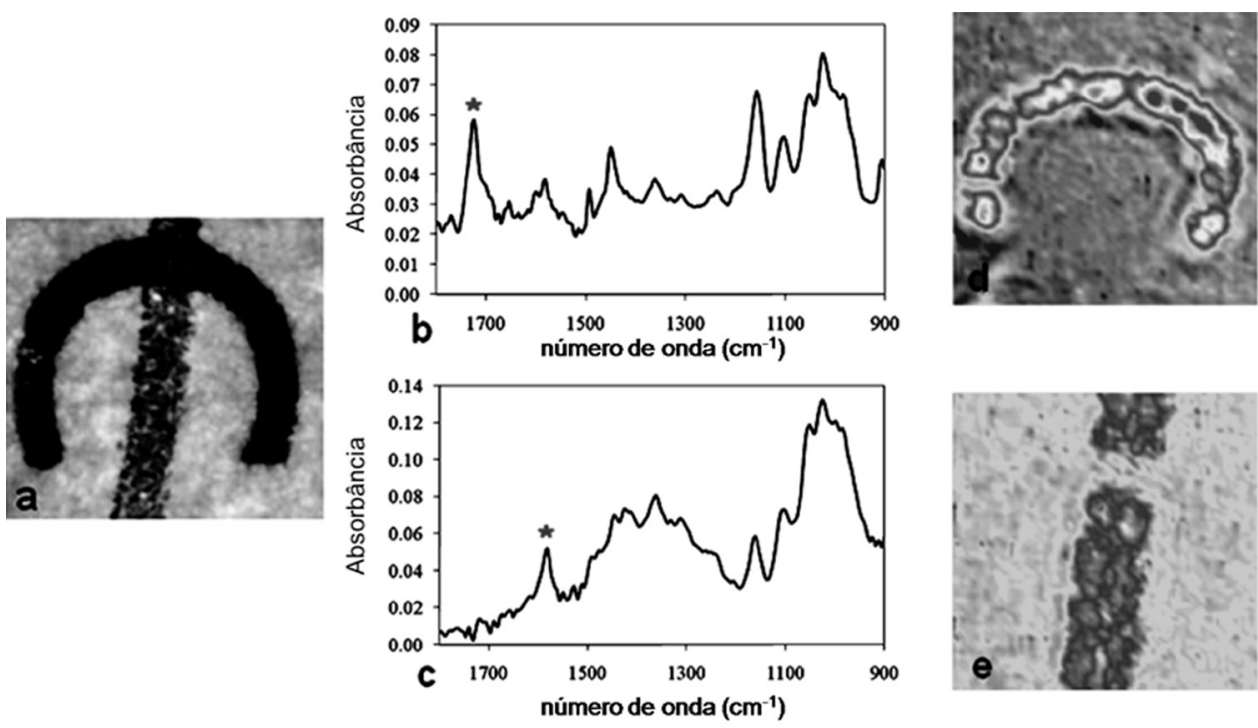

Figura 2. (a) Imagem de uma linha produzida por uma impressora a laser sobre uma linha escrita por uma caneta esferográfica; espectros de FT-IR para a impressora a laser (b) e a caneta esferográfica (c); imagens espectrais formadas para as linhas produzidas pela impressora a laser (d) e a caneta esferográfica (e) a partir das frequências 1724 e $1584 \mathrm{~cm}^{-1}$, respectivamente. Adaptada da ref. 2

como $1724 \mathrm{~cm}^{-1}$ (estiramento $\mathrm{C}=\mathrm{O}$, poliestireno-coacrilato) para a impressora a laser e $1584 \mathrm{~cm}^{-1}$ (estiramento $\mathrm{C}=\mathrm{C}$, resina epóxido) para a caneta esferográfica, foi possível produzir imagens espectrais mostrando a distribuição espacial dos materiais, Figuras $2 \mathrm{~b}-\mathrm{c}$. Analisando as imagens dos componentes isolados, Figuras 2d-e, uma imagem descontínua é observada para a caneta esferográfica, evidenciando que a mesma corresponde à linha inferior do traço. Logo, a impressora a laser corresponde à linha superior.

Foi também estudada a linha produzida pela caneta esferográfica sobre outra produzida por uma impressora a laser. Neste caso, a interpretação se torna um pouco mais complicada, pois ao analisar a imagem formada para a impressora a laser, nenhuma descontinuidade foi observada, como era de se esperar. Isso se deve à composição química do toner absorver fortemente na região do infravermelho, dificultando assim a interpretação da sequência dos traços. A distinção foi bem sucedida quando os autores observaram a região de interseção, onde uma coloração intensa é observada apenas para a imagem da linha produzida pela caneta esferográfica, evidência de que a mesma está sobre a linha da impressora a laser.

Baixas resoluções espectrais foram obtidas a partir de cruzamento de traços produzidos por outras impressoras, como ink-jet. A forte interação da composição química da tinta desta impressora com a superfície do papel interfere diretamente na aquisição das imagens espectrais. A substituição do cristal utilizado para as medidas de ATR poderia ser uma alternativa para a resolução deste problema. $\mathrm{O}$ germânio, por exemplo, possui um maior índice de refração $(\approx 4,0)$ e, proporcionalmente, uma menor capacidade de penetração do que o ZnSe. Este foi testado com o objetivo de reduzir a interferência provocada pelo papel. Entretanto, nenhum êxito foi obtido. ${ }^{2}$

Os autores também estudaram a sensibilidade da técnica na análise de interseção de linhas homogêneas produzidas por canetas esferográficas de composição química similar. Novamente, a técnica mostrou-se incapaz para a resolução deste problema. Conclui-se que, apesar da microespectroscopia no IR ser um método não destrutivo, sem a necessidade de realizar qualquer preparação de amostras, esta não é a técnica mais adequada para a análise forense de documentos, devido ao grande número de interferentes químicos presentes na composição da tinta e do papel, cujas vibrações de absorção, na maioria dos casos, sobrepõem-se à frequência vibracional analisada.
Esta técnica se mostra limitada na análise de interseções de traços em documentos questionados. Entretanto, se a aquisição dos dados for correlacionada a métodos quimiométricas como MCR (multivariate curve resolution), seria possível construir imagens a partir de padrões correspondentes a cada espectro característico e não apenas a uma única frequência específica. ${ }^{46}$

\section{Espectroscopia Raman}

A espectroscopia Raman vem se tornando uma ferramenta muito importante na análise de problemas forenses, como a comparação de tintas e também no sequenciamento do cruzamento de traços. ${ }^{6}$ Irradiando-se a amostra com uma potente fonte de laser de radiação monocromática no visível ou no infravermelho próximo, têm-se os espectros Raman, que, em geral, fornecem informações complementares aos correspondentes no IR. ${ }^{47}$

Claybourn e colaboradores ${ }^{5}$ estudaram o uso de um microscópio Raman confocal na análise comparativa de tintas, cruzamento de linhas e falsificação de documentos. Para prevenir interferência com o substrato, os espectros foram obtidos focando o laser sobre uma única fibra de papel, que foi revestida pela tinta a ser analisada utilizando dois comprimentos de onda de excitação do laser a 782 e $514 \mathrm{~nm}$; entretanto, o último mostrou-se mais eficiente.

Dentro do trabalho, uma série de canetas esferográficas de coloração preta foi analisada. Um "perfil espectral" distinto foi obtido para cada marca comercial (Bic ${ }^{\circledR}$ Fine, Colourplay, Pilot ${ }^{\circledR}$ BP-GP). Além disso, casos reais de fraudes foram estudados, a fim de averiguar a eficiência da técnica. As Figuras 3a-b mostram dois documentos, onde os algarismos "7" e "4" são suspeitos de falsificação. Os resultados obtidos no primeiro caso, Figura 3a, mostram espectros idênticos, quando analisadas diferentes posições do algarismo "7". Já para o algarismo "4", Figura 3b, espectros Raman bem distintos são observados. A parte superior do algarismo " 4 ", ou seja, a parte falsificada apresenta uma resposta Raman com domínio fluorescente, enquanto que a parte inferior, parte autêntica, mostra um espectro Raman com baixo deslocamento da linha base devido à fluorescência. ${ }^{5}$

Diferentemente do FTIR, a técnica Raman consegue distinguir vários tipos de tintas com composição química bem similar como, por exemplo, as canetas esferográficas de coloração preta. Análises 

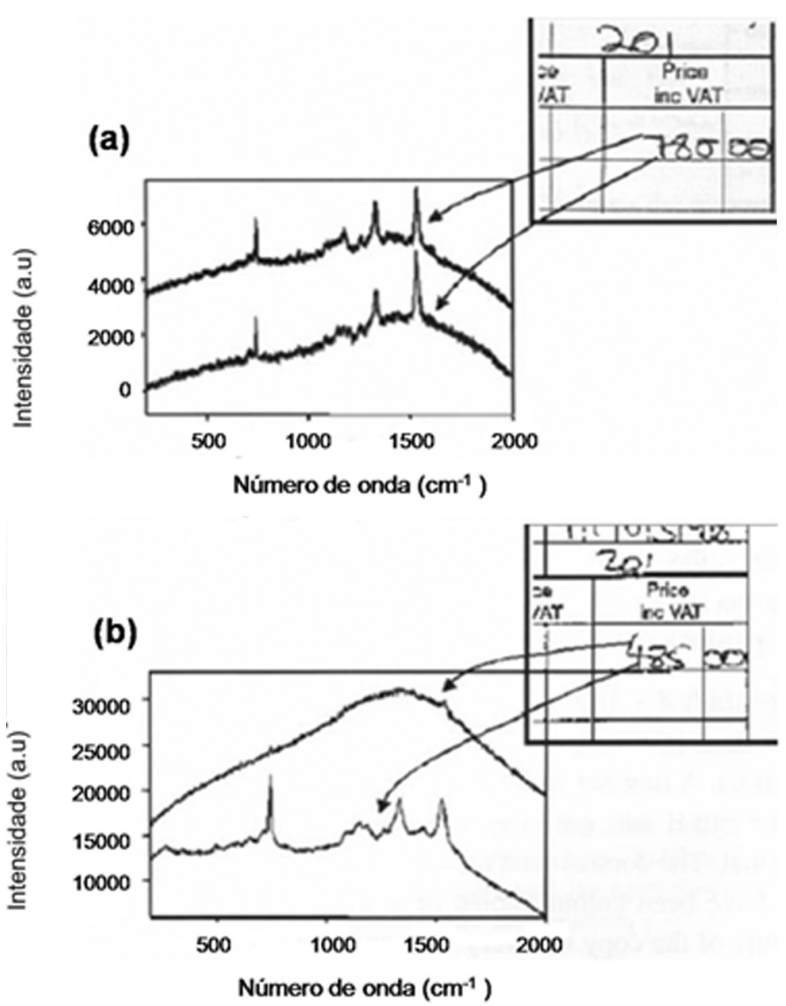

Figura 3. Espectros Raman a partir dos números suspeitos (a) "7" $e(b)$ "4". Adaptada da ref. 5

de cruzamento de traços podem também ser realizadas, independemente da composição e interação química existente entre a tinta e o substrato evitando, assim, a ocorrência de resultados falso-positivos. ${ }^{6}$

A técnica Raman vem se mostrando bastante promissora para a análise de tintas envolvendo falsificação de documentos; entretanto, poucos trabalhos são descritos na literatura. ${ }^{5,6}$ Para problemas envolvendo datação de tintas, por exemplo, nenhuma publicação foi encontrada utilizando esta técnica.

Imagine uma situação em que uma caneta de composição química idêntica tiver sido empregada na prática de crime, sendo o tempo a única variável. Seria possível estudar a autenticidade do documento investigado? A resposta para esta pergunta é discutida na próxima seção.

\section{Espectrometria de massas (LDI-MS, MALDI-MS e EASI-MS)}

A datação de tintas em documentos questionados é, sem dúvida, uma análise controversa. Se a idade de uma tinta for conhecida, a falsificação de documentos envolvendo canetas esferográficas certamente seria de fácil resolução.

Recentemente, um novo conjunto de técnicas de ionização em espectrometria de massas foi desenvolvida. ${ }^{17,19,20}$ Os primeiros estudos direcionados para a análise de tintas em documentos surgiram no período de 2005-2006. ${ }^{16,18}$ Laser desorption ionization mass spectrometry (LDI-MS) e matrix-assisted laser desorption/ionization mass spectrometry (MALDI-MS) são ferramentas analíticas muito utilizadas na análise de corantes. O uso de MALDI-MS e LDI-MS pode envolver pouca preparação de amostra. ${ }^{48,49}$ Posteriormente, elas são colocadas sobre uma superfície metálica, introduzidas em uma câmara de ionização e irradiadas com um laser pulsado $\left(\mathrm{N}_{2}, 337 \mathrm{~nm}\right.$, $3 \mathrm{~ns}, \approx 20 \mu \mathrm{m}$ ). Ocorre a dessorção e a ionização do analito, sendo os íons formados atraídos para o analisador de massas. ${ }^{16}$

Weyermann e colaboradores ${ }^{16}$ investigaram o envelhecimento dos corantes violeta de metila (MV) e violeta de etila (EV), usados em canetas esferográficas de coloração azul. Envelhecimentos acelerados (temperatura, luz, e umidade) e naturais (1 ano) foram estudados. Além disso, foram analisados diversos métodos de preparação de amostras e seus possíveis efeitos nos estudos de envelhecimento.

Espectros de MALDI-MS para os corantes MV e EV a um $\mathrm{t}=$ 0 s, são mostrados na Figura 4a. Os íons mais intensos correspondem às espécies $\mathbf{M}^{+}$de $m / z, 372$ e 456, respectivamente. Após $6 \mathrm{~h}$ de degradação fotoquímica, vários outros íons de menor valor de $\mathrm{m} / \mathrm{z}$, são observados, Figura $4 \mathrm{~b}$. Estes íons são formados a partir da perda progressiva de grupos $\mathrm{C}_{\mathrm{n}} \mathrm{H}_{2 \mathrm{n}}$. Para o MV, cinco produtos de degradação são formados com redução de 14 u $(\mathrm{m} / \mathrm{z}, 358,344,330$, 316 e 302). Para o EV, cinco produtos são formados com redução de 28 u $(\mathrm{m} / \mathrm{z}, 428,400,372,344$ e 316$)$ e 5 com redução de 14 u $(\mathrm{m} / \mathrm{z}, 442,414,386,358,330$ e 302$)$. Essa degradação pode ser quantificada pela fórmula: $\mathrm{RPA}=\left(\mathrm{A}_{\mathrm{i}} / \mathrm{A}_{\text {total }}\right) \times 100$, onde $\mathrm{A}_{\mathrm{i}}$ é o valor da intensidade absoluta de um íon de $m / z=\mathrm{i}$, e $\mathrm{A}_{\text {total }}$ é a somatória dos valores de intensidade absoluta do íon precursor e os seus produtos de degradação.

As Figuras 5a-c mostram os gráficos de envelhecimento acelerado para os corantes MV e EV, sob condições de calor e luz. Curvas de RPA $v s$ tempo foram obtidas. Um decaimento exponencial foi observado em ambos os casos, Figuras 5a-b, onde valores menores de $\mathrm{RPA}_{372} \mathrm{e} \mathrm{RPA}_{456}$ correspondem a uma maior degradação dos corantes. Pode-se observar que a luz é o catalisador majoritário nos estudos de estabilidade dos corantes, fazendo com que as curvas alcançassem um patamar constante após $3 \mathrm{~h}$ para o MV, $\mathrm{RPA}_{372}=30 \%$, Figura 5a, e $50 \mathrm{~h}$ para o $\mathrm{EV}, \mathrm{RPA}_{456}=30 \%$, Figura $5 \mathrm{~b}$. Isso se deve ao fato dos corantes absorverem na região de emissão da luz de xenônio (valores máximos de absorção em $588 \mathrm{~nm}$ para o MV e $592 \mathrm{~nm}$ para o EV) provocando, assim, a fotodegradação via demetilação e decomposição conjugada do anel aromático. Os autores também observaram que a degradação fotoquímica pode ser catalisada pela presença de umidade, onde valores de $\mathrm{RPA}_{372}=30 \%$ para o $\mathrm{MV}$ e $\mathrm{RPA}_{456}=80 \%$ para o $\mathrm{EV}$ foram obtidos após $9 \mathrm{~h} .{ }^{19}$ Além da grande variabilidade existente no estudo de estabilização dos corantes usados em canetas esferográficas azuis, as técnicas MALDI-MS e LDI-MS apresentam algumas limitações para as análises de rotina em laboratórios forenses, pois, dependendo da energia e do tipo de laser empregado a degradação dos corantes pode ocorrer durante o processo de ionização. Estudos de degradação natural foram feitos com canetas esferográficas azuis. Os autores não observaram variação na estabilidade do corante, quando o mesmo foi exposto à luz do dia sobre a superfície de um papel, durante 349 dias. Após esse período, fortes sinais correspondentes a produtos de degradação foram observados. Entretanto, nenhuma correlação entre a cinética de degradação dos corantes estudados foi feita com tintas esferográficas de documentos antigos (entre 20 e 30 anos). Em geral, esse trabalho apresenta resultados inovadores e importantes para estudos futuros de datação de tintas. Entretanto, o uso desta técnica apresenta algumas desvantagens: a) destruição do documento - é necessário conduzir parte do papel contento o pigmento para a plataforma do MALDI; b) uso de matrizes orgânicas - otimização e a reprodutibilidade das condições de ionização nem sempre é um processo simples; c) uso de solventes - caso seja necessário extrair o corante do papel, os estudos de contraprova de documentos questionados não poderiam ser realizados; d) laser - dependendo de sua potência, pode haver degradação do analito. É importante ressaltar que esse trabalho apresenta grandes méritos e, como consequência, tem despertado o interesse de vários grupos de pesquisa que desenvolveram métodos de ionização mais modernos, pouco destrutíveis e rápidos na análise de documentos questionados. Entre os sistemas de ionização recentemente empregados em condições ambientes (ou seja, ionização do analito à pressão atmosférica sem preparo de amostra), pode-se citar EASI-MS, ${ }^{17}$ DESI-MS ${ }^{20}$ e DART-MS. ${ }^{19}$ Em 

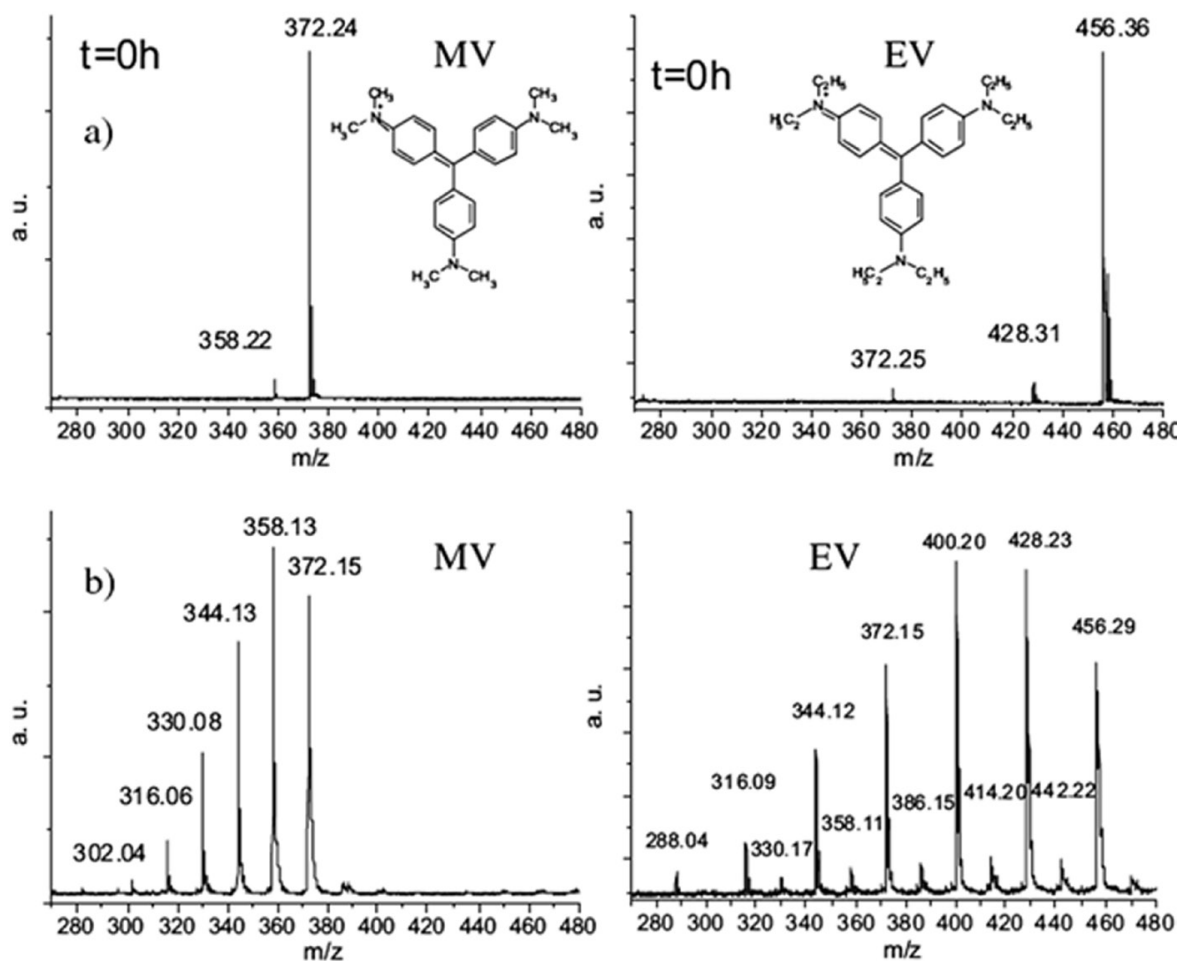

Figura 4. (a) Espectros de MALDI(+)-MS para os corantes de violeta de metila, $M V:\left[M^{+}=372,2\right.$ u] e violeta de etila, VE: $\left[M^{+}=456,3 u\right]$ dissolvidas em etanol em $t=0 \mathrm{~s}$. (b) Espectros de MALDI(+)-MS para os corantes ME e EV, depois do envelhecimento acelerado com lâmpada de xenônio onde $t=6$ h. Adaptada da ref. 16

questão de segundos, é possível analisar vários fatores importantes na área de documentoscopia.

\section{EASI-MS}

Em 1994, Hirabayashi e colaboradores ${ }^{50-52}$ também revolucionaram o campo da espectrometria de massas, introduzindo uma técnica de ionização à pressão atmosférica (API), nomeada de ionização por spray sônico (SSI). A SSI introduziu um novo conceito de ionização em espectrometria de massas. Os íons puderam ser produzidos sem aplicação de nenhuma voltagem, radiação ou aquecimento, onde as gotas carregadas eram produzidas usando apenas um spray contendo uma solução de metanol acidificado a uma velocidade sônica. As gotas carregadas (com cargas positivas e negativas) surgem a partir de uma distribuição não balanceada estatisticamente de espécies $\mathrm{M}^{+}$e $\mathrm{M}^{-}$. Nenhum aquecimento é necessário para dessolvatação das gotas; logo, ambos os íons gasosos $[\mathrm{M}+\mathrm{H}]^{+}$e $[\mathrm{M}-\mathrm{H}]^{-}$, dependendo da natureza do analito, surgem via SSI e, portanto, apenas pelo auxílio de nitrogênio comprimido (ou ar, se este for usado). ${ }^{53,54}$ Poucos segundos são necessários para dessorver e ionizar o analito a partir da superfície investigada em condições ambientes e, devido a sua simplicidade, essa técnica foi nomeada como easy ambient sonic-spray ionization (EASI, Figura 6), a primeira técnica ambiente baseada em SSI. ${ }^{55}$

EASI-MS tem sido aplicado com sucesso para análise dos mais diversos analitos em matrizes como fármacos, ${ }^{53}$ perfumes,${ }^{56}$ sufactantes, ${ }^{57}$ óleos vegetais, ${ }^{58}$ biodiesel,${ }^{59}$ própolis, ${ }^{60}$ petróleo ${ }^{61}$ e derivados.${ }^{62}$

Dentro do contexto forense, os trabalhos usando a técnica E-SI-MS ${ }^{17}$ demostraram que outros corantes empregados em canetas esferográficas, além do MV, sofrem degradação fotoquímica. Entre estes, Basic Blue 26 ( $\mathrm{m} / \mathrm{z}, 470)$, Basic Blue 7 ( $\mathrm{m} / \mathrm{z}$ 478), Basic Violet e o Basic Red 1, (ambos de $m / z$ 443) foram detectados. Em alguns casos, corantes como niquelato de ftalocianina $(\mathrm{m} / \mathrm{z}, 571)$ e 1,3-dimetil1,3-ditoliguanidida $(\mathrm{m} / \mathrm{z}, 268)$ são estáveis, não sofrendo degradação quando expostos à luz incandescente durante $72 \mathrm{~h}$. Documentos antigos fornecidos pela Polícia Federal foram também analisados (1987, 1993, 1997 e 2001). O corante MV novamente funcionou como um "relógio químico". Os autores afirmam que a degradação natural ocorrida com os documentos antigos são fatores não controláveis, onde cada documento pode ter sido armazenado ou exposto a condições diferentes, sendo necessário, portanto, um grande número de documentos para a realização de uma metodologia de validação analítica. Entretanto, uma estimativa é feita para um documento de 10 anos, onde os cálculos de $\mathrm{RPA}_{372}$ mostraram corresponder a um envelhecimento acelerado de $6 \mathrm{~h}$. Outro resultado interessante é que a variação do $\mathrm{RPA}_{372}$ com o tempo apresenta uma relação linear quando se usa uma lâmpada incandescente, diferentemente do trabalho anterior, onde o valor de $\mathrm{RPA}_{372}$ se estabiliza em $30 \%,{ }^{16}$ corroborando a importância da elaboração de metodologias de validação analítica onde os valores de $\mathrm{RPA}_{372}$ obtidos pelos estudos de envelhecimentos acelerados e naturais poderiam ser correlacionados.

Os autores também mostram que é possível analisar uma interseção homogênea de traços feitos por canetas esferográficas azuis e números suspeitos de falsificação.

Recentemente, a falsificação de dinheiro é outro grande problema que a Casa da Moeda vem enfrentando no Brasil. Os falsificadores vêm aprimorando suas técnicas de falsificação, conseguindo "imitar" os vários elementos de segurança que estão presentes no papel-moeda, adicionados no processo de impressão. ${ }^{43}$

A obtenção do perfil químico do dinheiro torna-se uma metodologia eficiente para as investigações criminais no combate à falsificação do dinheiro nacional. A autenticidade das principais moedas (real, dólar e euro) pode ser averiguada em poucos segundos, Figura 7. Para o espectro de EASI-MS correspondente à nota de 50 reais, Figura 7a, uma série de íons diagnósticos é detectada com valores de $m / z$ de 391, 413, 429, 803 e 819. Na maioria dos casos, é comum também encontrar como contaminante o íon de $m / z$ 304, que corresponde à 
(a)

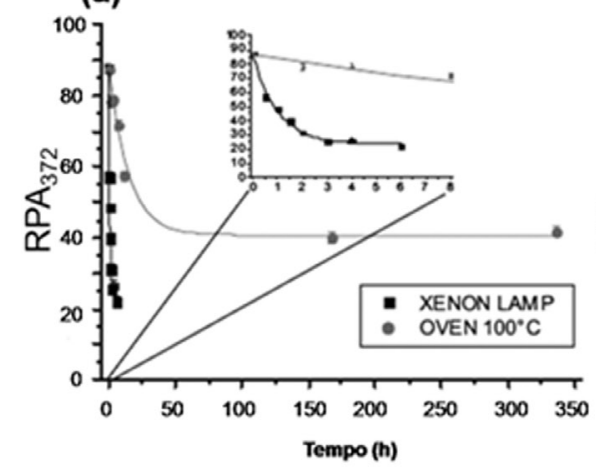

(b)

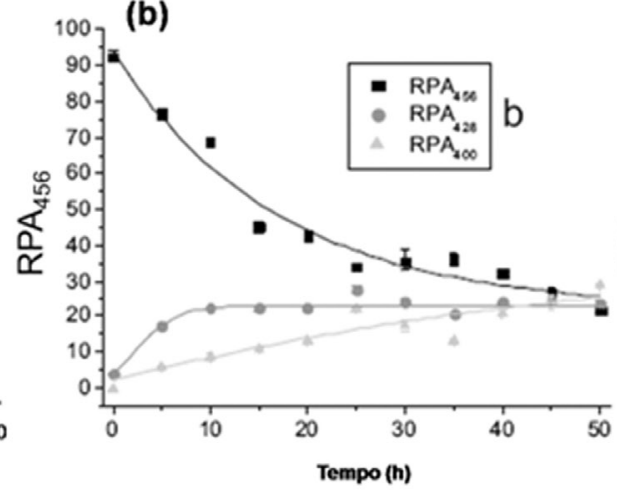

(c)

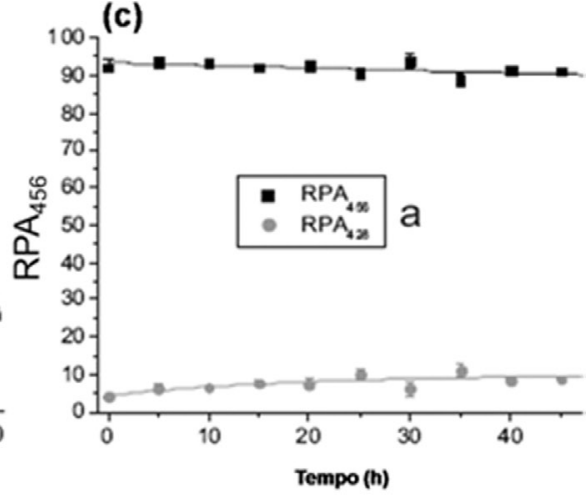

Figura 5. Comparação da degradação do (a) MV e $(b-c) E V$ : fotoquímica $(t=7$ dias) vs térmica. Adaptada da ref. 16

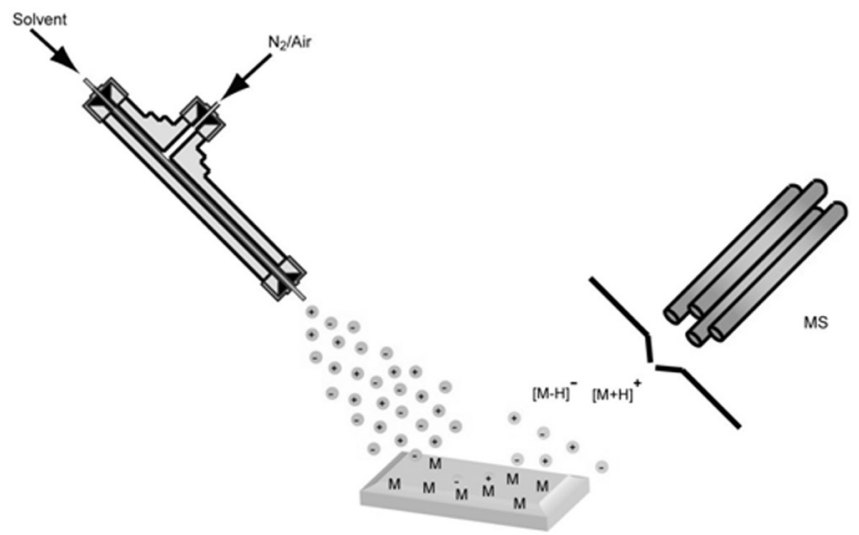

Figura 6. Diagrama esquemático da técnica EASI-MS. Pressão $\mathrm{N}_{2}$ de 30 bar e vazão do solvente da ordem de $20 \mu \mathrm{L} \mathrm{min}^{-1}$. Adaptada da ref. 55

molécula de cocaína protonada. Como os dados obtidos foram feitos no EASI(+)-FT-ICR MS (easy ambient sonic-spray ionization Fourier transform ion cyclotron ressonance mass spectrometry), eles possuem altíssima resolução e exatidão, adicionado à possibilidade de se realizar experimentos de $\mathrm{MS}^{n}$ (multistage mass spectrometry). Portanto, é fácil elucidar a estrutura desses íons diagnósticos. A maior parte deles correspondem ao plastificante bis(2-etil-hexil)ftalato, detectado como $[\mathrm{M}+\mathrm{H}]^{+}$de $m / z$ 391; $[\mathrm{M}+\mathrm{Na}]^{+}$de $m / z$ 413; $[\mathrm{M}+\mathrm{K}]^{+}$de $m / z$ $429,[2 \mathrm{M}+\mathrm{Na}]^{+}$de $m / z 803$ e $[2 \mathrm{M}+\mathrm{K}]^{+}$de $\mathrm{m} / z, 819$. O íon de $\mathrm{m} / \mathrm{z}$ 494 é atribuído ao biocida, que é um sal de amônio quaternário, dihexadecildimetrila de amônio.

Amostras de notas de dólar e euro foram também analisadas pelo EASI-FT-ICR MS (Figuras 7b-c). Foi observado que os íons diagnósticos de $m / z, 391,413,429,803$ e 831 presentes nas notas brasileiras não são detectados. Para as notas estrangeiras, o perfil químico é dominado por distribuições oligoméricas de íons correspondentes a alcoóis graxos propoxilados, separados por unidades de repetição de $\mathrm{m} / z$ 58. Essas distribuições, no entanto, são bastante distintas para ambas as notas. Para o euro, essa distribuição é centrada na região de $m / z$ de 900 (Figura 7c), onde os oligômeros detectados são espécies $[\mathrm{M}+\mathrm{Na}]^{+}$. Para o dólar, a distribuição oligomérica é centrada na região de $m / z$ de 500 , formando espécies $[\mathrm{M}+\mathrm{H}]^{+}$, Figura $1 \mathrm{Sb}$, material suplementar. ${ }^{63}$

Perfis químicos foram também obtidos para as notas falsas reproduzidas no Laboratório Thomson usando 3 diferentes marcas de impressoras: inkjet, phaser e laserjet (Figuras 1Sa-c, material suplementar). Os íons detectados para as impressoras inkjet e phaser correspondem a uma série oligomérica de $\mathrm{m} / \mathrm{z}, 300-900$ e $\mathrm{m} / \mathrm{z}, 700$ 1300, respectivamente (Figuras $1 \mathrm{Sa}-\mathrm{b}$, material suplementar). Em contrapartida, o perfil químico para a impressora laserjet apresenta poucos íons marcadores $(m / z, 629,734,793$ e 835), Figura $1 \mathrm{Sc}$, material suplementar. É bastante nítida a diferença dos perfís químicos obtidos entre as notas falsificadas (Figuras 1Sa-c) e autênticas (Figura 7a). Os íons marcadores presentes nas impressoras (notas falsas) correspondem a alcoóis graxos etoxilados e propoxilados, detectados como adutos de sódio, $[\mathrm{M}+\mathrm{Na}]^{+} .{ }^{63}$

\section{BALÍSTICA FORENSE}

A munição é a principal prova material estudada dentro da balística. Ela é constituída por projétil, estojo, carga de projeção e carga de inflamação ou de espoletamento, Figura 2S, material suplementar. ${ }^{64}$ Dentro da balística forense, talvez a prática mais realizada seja a identificação do atirador por meio dos resíduos de tiro (GSR).

A carga de inflamação, também chamada de mistura iniciadora ou primer, é responsável por deflagrar a combustão da pólvora (carga de projeção) contida no estojo e a expulsão do projetil através do cano da arma. A proporção e os elementos presentes na mistura iniciadora variam de acordo com o tipo de espoleta (fogo central ou circular) e de munição. Geralmente, a espoleta é constituída por um composto explosivo (estifnato de chumbo), um oxidante (nitrato de bário, dióxido de chumbo ou nitrato de chumbo), um combustível (trissulfeto de antimônio ou siliceto de cálcio), sensibilizantes (trinitrotolueno, tetraceno) e aglutinantes (goma-arábica, resinas celofane e goma-laca). Os elementos $\mathrm{Pb}$, Sb e Ba são os principais marcadores químicos presentes nos resíduos inorgânicos produzidos por disparos de armas de fogo. Além dos resíduos deixados pela espoleta, a pólvora também pode ser analisada.

A pólvora tem a função de expelir, pela pressão dos gases, o projétil. Há dois tipos de pólvora: a pólvora negra, com fumaça, e a pólvora sintética, sem fumaça.

A pólvora negra, raramente utilizada nos dias atuais, é formada quimicamente por uma mistura de carvão, salitre (nitrato de potássio) e enxofre, em proporções variáveis, gozando da propriedade de inflamar-se rapidamente, resultando assim em uma combustão intensa e com grande produção de fuligem. Inflamada em local fechado, a pólvora negra libera gases desenvolvendo quase instantaneamente o máximo de sua força viva. Os principais produtos da combustão em volume são gases (43\%), sólidos (55\%) e água (1\%). ${ }^{64,65}$

Um substituto moderno da pólvora negra é a pólvora sintética, onde outros aditivos são adicionados com funções específicas, contribuindo diretamente para a vida útil da munição, sendo eles: nitrocelulose (oxidante); nitroglicerina, ftalato de dimetila ou butila, glicerina (plastificantes); difenilamina, 2-ou 4-nitrofenilamina, nnitrosodifenilamina, dinitrotolueno, n-metil-p-nitroanilina, metil ou etil entralina, resorcinol (estabilizantes); sulfato de potássio, nitrato 


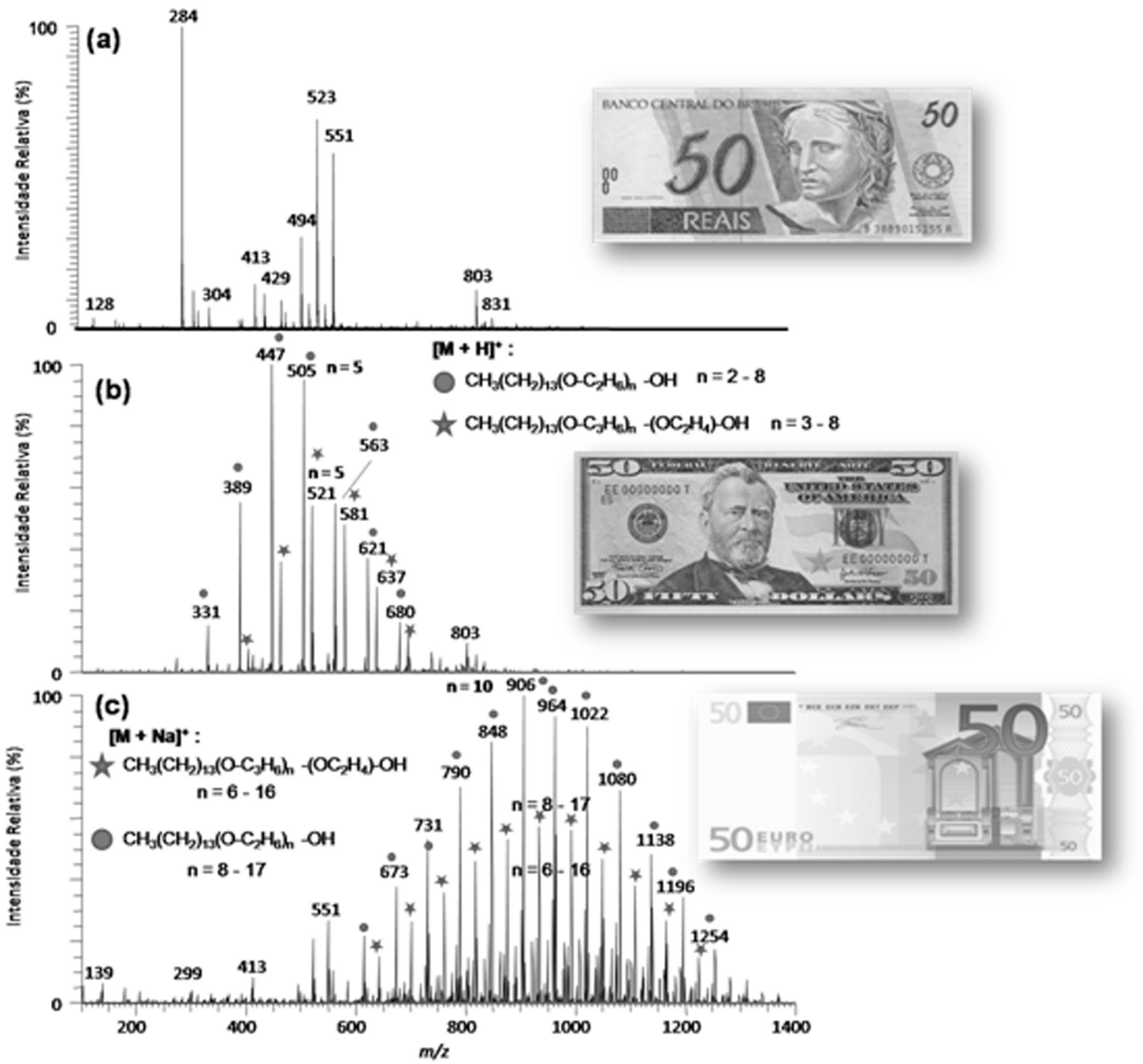

Figura 7. EASI(+)-FT-ICR MS para notas autênticas de cédulas de 50 reais (a), 50 dólares (b) e 50 euros (c). Adaptada a partir da ref. 63

de potássio, grafite (aditivos orgânicos). Alguns compostos orgânicos são considerados irrelevantes para identificação de GSR orgânicos por possuírem outras fontes como a nitrocelulose, por exemplo, que é encontrada em laquês e indústrias farmacêuticas, assim como a nitroglicerina e a difenilamina que também podem ser oriundas de outras fontes. Diferentemente, os estabilizantes à base de centralina são aplicados unicamente na fabricação de munições. Atualmente, esses compostos têm sido usados como marcadores na análise de GSR orgânicos presentes após a combustão da pólvora, podendo ser encontrados no estojo ou nas mãos do atirador. ${ }^{64,65}$

Espectrometria de fluorescência de raios-X (XRF) e espectrometria de massas com plasma indutivamente acoplado (ICP-MS)

A XRF permite identificar e quantificar a composição elementar de uma grande variedade de amostras nos estados sólido ou líquido, com mínima ou nenhuma preparação prévia. ${ }^{66} \mathrm{~A}$ velocidade de análise, aliada ao fato da técnica ser não destrutiva e multielementar possibilitam diversas aplicações na área forense, entre elas a análise de resíduos inorgânicos de disparo de armas de fogo, através da detecção dos elementos químicos comuns nos propelentes. ${ }^{35-37}$
Berendes e colaboradores ${ }^{35}$ estudaram a versatilidade da espectrometria de fluorescência de raios-X milimétrica por dispersão de energia ( $\mathrm{m}$-XRF), na obtenção de imagens de GSR produzidas por munições convencionais (contendo os elementos $\mathrm{Pb}, \mathrm{Ba}$ e $\mathrm{Sb}$ ) e munições denominadas ambientais. Três modos distintos de análise foram testados: a) o escaneamento pontual, b) de linha e c) construção de imagens "elementares" através do acoplamento de uma câmera de vídeo. Embora o tempo de análise da $\mathrm{m}$-XRF seja maior do que os métodos colorimétricos (4 h para a obtenção das imagens), a preparação de amostra não é necessária, tornando a técnica atrativa para a área de balística, além de ter um custo acessível.

Inicialmente, os autores avaliaram a capacidade da técnica na obtenção de imagens elementares. Usando munições convencionais (com metais pesados na espoleta), as imagens obtidas pela m-XRF mostram a distribuição de $\mathrm{Pb}$ e $\mathrm{Ba}$ produzidos por disparos realizados a uma distância de $5 \mathrm{~cm}$ do tecido de algodão branco usado como alvo, Figuras 3Sa e 3Sc, material suplementar. Foi observada grande abundância de ambos os elementos, sendo que o Ba se encontra mais próximo à perfuração. Quando comparado com o tecido revelado pelo reagente químico rodizionato de sódio, os dois elementos também foram identificados via formação de complexos coloridos: rodizionato de bário (vermelho) e rodizionato de chumbo (roxo), Figura $3 \mathrm{Sb}$, 
material suplementar. Este teste não é capaz de identificar o terceiro elemento, o Sb. Além disso, o Ba encontrou-se distribuído nas extremidades da perfuração e em baixa abundância. Isso se deve ao fato da cor produzida pelo $\mathrm{Pb}$ (roxo) suprimir a coloração vermelha do $\mathrm{Ba}$, mostrando, além da baixa especificidade desta técnica, problemas relativos a interferências causadas por elementos mais abundantes. ${ }^{35}$

Um espectro de $\mathrm{m}$-XRF pontual é mostrado para os GSR produzidos em um tecido alvo posicionado a $5 \mathrm{~cm}$ da boca do cano da arma, Figura 3Sd, material suplementar. Além dos três elementos constituintes da espoleta $(\mathrm{Pb}, \mathrm{Ba}, \mathrm{Sb})$, foi possível identificar resíduos oriundos do estojo (latão) ou da camisa do projétil, como o $\mathrm{Cu}$. A m-XRF, além de detectar os GSR inorgânicos depositados sobre tecidos, permite estimar a distância provável do disparo. As Figuras 3Se-g, material suplementar, mostram que à medida que a distância entre o alvo e a arma aumenta ( 5 para $40 \mathrm{~cm}$ ) a construção da imagem elementar do $\mathrm{Pb}$ se torna menos abundante. Os autores também mostraram que é possível detectar GSR inorgânicos presentes nas mãos do atirador. ${ }^{35}$

Analisando os GSR inorgânicos produzidos pelas munições ambientais; a m-XRF detecta sua composição com facilidade. Linhas de emissão para os elementos $\mathrm{Ti}, \mathrm{Cu}$ e $\mathrm{Zn}$ foram detectadas sobre a pele de um animal (porco), após um disparo a $5 \mathrm{~cm}$ do alvo, Figura 4Sb, material suplementar. Os elementos Ti e Zn fazem parte da composição da mistura iniciadora de algumas munições ambientais. ${ }^{64}$ Também é possível obter um mapeamento elementar para as linhas de emissão correspondentes ao elemento Ti, Figura 4Sa, material suplementar.

A XRF pode ser uma técnica promissora para análise de GSR inorgânicos. Entretanto, poucos trabalhos existem na literatura mencionando a sensibilidade desta técnica direcionada para o estudo de balística ${ }^{67}$ No caso de grandes distâncias entre o alvo e o atirador (> $100 \mathrm{~m}$ ), essa técnica se torna inviável para análise de GSR nas vestes da vítima.

Recentemente, algumas publicações sugerem a utilização de ICPMS para análise de GSR. ${ }^{38}$ Sarkis e colaboradores ${ }^{38}$ mostraram que é possível detectar GSR inorgânico em concentrações menores que $1 \mathrm{mg} \mathrm{L}^{-1}$, quando se utiliza ácido etilenodiaminotetracético (EDTA) como agente complexante para remoção dos GSR das mãos de 40 atiradores. Diagramas ternários foram construídos para mostrar a concentração relativa dos metais $\mathrm{Pb} / \mathrm{Ba} / \mathrm{Sb}$ em função dos GSR produzidos por diferentes armas. Uma distribuição distinta é observada apenas para GSR produzidos por pistolas de calibre .40. Já para os GSR produzidos por pistolas calibre $9 \mathrm{~mm}$, foi observada uma grande variação nos resultados. ICP-MS, sem dúvida, é uma técnica que poderia ser empregada na detecção de GSR, em conjunto com o SEM/EDX. Com a ajuda do sistema de ablação a laser, informações mais detalhadas sobre a arma ou da munição utilizada poderiam ser obtidas. A principal desvantagem da técnica está no custo da análise por amostra. Embora um grande volume de argônio seja utilizado, o custo por análise poderia ser reduzido se grandes números de amostras fossem analisados diariamente.

\section{Eletroforese capilar (CE) e cromatografia líquida (LC)}

A eletroforese é um método de separação baseado nas velocidades de migração diferenciais de espécies carregadas em um campo elétrico de corrente contínua. Esta técnica foi desenvolvida inicialmente pelo químico sueco Arne Tiselus, em 1930, para o estudo de proteínas de soro sanguíneo (Prêmio Nobel de Química, 1948). ${ }^{47}$

Dentro da balística forense, Morales e colaboradores ${ }^{11}$ desenvolveram um método para aplicar a CE na análise de GSR orgânicos (como nitroglicerina; resorcinol; 2,3-dinitrotolueno, 2,4-dinitrotolueno, 2,6-dinitrotolueno; dimetilftalato, dietilftalato e dibutilftalato; metilcentralina e etilcentralina); e GSR inorgânicos (Fe, Ba, Ca, $\mathrm{Mg}, \mathrm{Al}, \mathrm{Ni}, \mathrm{Zn}, \mathrm{Pb}$ e $\mathrm{Cu}$ ), simultaneamente. Com isso, uma maior especificidade na análise de GSR poderá ser alcançada. A condição ótima foi alcançada utilizando tetraborato de sódio de $40 \mathrm{mM}(\mathrm{pH}$ 9,2), CDTA (ácido tetracético diaminociclo-hexano) 0,5 mM, agente complexante; SDS (dodecilsulftato de sódio) $16 \mathrm{mM}$ ou acima de 20 $\mathrm{mM}$; comprimento e diâmetro interno do capilar de $75 \mu \mathrm{m}$ e 79,2 cm, respectivamente; voltagem positiva de $30 \mathrm{kV}$; injeção eletrodinâmica de 5 s e 0,5 psi e temperatura de $25^{\circ} \mathrm{C}$.

Após a otimização da metodologia, limites de detecção (LOD) na faixa de $0,1-11\left(\mathrm{mg} \mathrm{L}^{-1}\right)$ e um excelente coeficiente de correlação $\left(r^{2}>0,99\right)$ foram encontrados para todas as amostras. A Figura 5Sa, material suplementar, mostra o eletroferograma dos GSR orgânicos e inorgânicos sob condições ótimas, onde todos os padrões estudados foram identificados. ${ }^{11}$

GSR de amostras reais também foram analisadas. Uma pistola calibre .22 e dois revólveres calibres .32 e .38 foram usados para testar a eficiência da técnica desenvolvida. GSR foram coletados das mãos do atirador após 1 e 3 disparos. O procedimento de coleta também foi estudado e a condição ótima foi alcançada quando foi usado CDTA, SDS e borato para a remoção dos GSR na região palmar média da mão do atirador. Os resultados de eletroferograma para todas as armas analisadas mostraram que apenas resíduos inorgânicos foram detectados ( $\mathrm{Pb}, \mathrm{Zn}, \mathrm{Cu}, \mathrm{Ca}$ e Fe), Figura 5Sb, material suplementar. Para avaliar a confiabilidade da técnica, medidas de espectroscopia de absorção atômica eletrotérmica foram realizadas para quantificar os resíduos inorgânicos detectados. Uma boa concordância entre ambas as técnicas foi observada. A Figura 5Sb, material suplementar, mostra eletroferogramas dos resíduos coletados em condições reais usando um revólver calibre .32 , onde: $\mathrm{I}=$ branco; $\mathrm{II}=$ branco da palma da mão; III = resíduos coletados após 1 disparo; $\mathrm{IV}$ = resíduos coletados após 3 disparos. ${ }^{11}$

A balística forense poderia se beneficiar com um método confiável para detecção de GSR orgânicos, especialmente com o crescimento no número de munições ambientais. A eletroforese poderia ser uma alternativa, embora ainda seja necessário otimizar o método e a forma de coleta, uma vez que sob condições reais (não ótimas) não foi possível detectar os resíduos orgânicos.

Técnicas cromatográficas podem ser uma alternativa para solucionar a carência na área de balística forense. ${ }^{34,68}$ Em 2008, Perret e colaboradores ${ }^{34}$ confirmaram a presença de resíduos orgânicos de estabilizantes e explosivos (trinitrotolueno (TNT), nitroglicerina (NG), tetranitrato de pentaeritritol (PETN), ciclotrimetilenotrinitramina (RDX), difenilamina (DPA) e etilcentralina (EC)) usando LC/ MS-MS (liquid chromatography/tandem mass spectrometry). Baixos limites de detecção foram obtidos $\left(n \mathrm{~L} \mathrm{~L}^{-1}\right)$. Foram desenvolvidos procedimentos rápidos de extração. A sensibilidade da técnica foi testada em função da análise imediata após o manuseio do explosivo; $1 \mathrm{~h}$ após o manuseio do explosivo; 6 h após o manuseio do explosivo e, manuseio e lavagem com sabão e água. Os possíveis resíduos de explosivos foram removidos da pele de soldados através de swabs comerciais. Após a extração, o swab foi mergulhado em um tubo de vidro (vial) contento $1 \mathrm{~mL}$ de metanol. A solução foi centrifugada e $5 \mu \mathrm{L}$ do sobrenadante foram injetados diretamente no HPLC-MS (cromatografia líquida de alta eficiência acoplada com espectrômetro de massas). A aquisição dos espectros de massas foi realizada usando o modo de monitoramente de reação múltipla (MRM), sob duas condições diferentes: modo de aquisição de íons negativo, $-4500 \mathrm{~V}$, para a análise de NG, RDX, PETN e TNT e modo de aquisição de íons positivo, $+4500 \mathrm{~V}$, para análise de DPA e EC.

Com exceção do DPA e EC, todos os outros compostos foram encontrados nas mãos dos voluntários em concentrações na faixa de $\mu \mathrm{g} \mathrm{L}^{-1}$. Para o TNT, por exemplo, as concentrações variaram de 362, 63, 6 e $28\left(\mu \mathrm{g} \mathrm{L}^{-1}\right)$, em função das condições de amostragem acima, a-d. ${ }^{34}$ Esses resultados mostram que os resíduos orgânicos 
provenientes de explosivos e de disparo de armas de fogo apresentam uma baixa estabilidade, degradando-se em poucas horas. Portanto, a LC-MS poderia ser usada como uma importante metodologia para monitorar a presença dos GSR em locais de crimes, já que apresenta um baixo limite de detecção.

Os resultados mostram que os GSR orgânicos, em geral, possuem uma baixa estabilidade. Portanto, técnicas destinadas à análise desses compostos devem ser sempre utilizadas como complementares, evitando-se assim resultados falso-negativos. Até que se desenvolva uma técnica confiável para a detecção de ambas as classes de GSR, as metodologias destinadas a GSR inorgânicos serão sempre mais confiáveis.

\section{DROGAS DE ABUSO}

O uso de substâncias psicotrópicas, normalmente derivadas de plantas, na busca de experiências religiosas ou mesmo de prazer e bem-estar, remete a humanidade às próprias origens. Tais drogas atuam no sistema nervoso central (SNC), modificando o humor, a consciência, os sentimentos, as sensações, o estado de vigília, dentre outros. Porém, o uso abusivo, inconsequente e indiscriminado é um fenômeno mais recente e cada vez mais disseminado nas sociedades contemporâneas.

As substâncias químicas comumente usadas como drogas de abuso e que causam dependência psíquica e física podem ser classificadas em três grandes classes, de acordo com a sua principal ação no SNC: 1) depressores do SNC: opiáceos/opioides, etanol e barbitúricos;2) estimulantes do SNC: cocaína ou crack, anfetaminas, metanfetaminas (como MDMA) e anorexígenos; 3) pertubadores do SNC: drogas alucinógenas, como LSD, psilocibina, mescalina e canabinoides. ${ }^{69}$

A maioria dos métodos desenvolvidos para identificar a presença de drogas de abuso em dependentes químicos é aplicada a uma destas classes de compostos, onde vários procedimentos de preparo de amostras, um maior tempo de análise, ou várias corridas cromatográficas podem ser necessários. Dessa forma, métodos alternativos e mais eficientes que atendam a todas as classes de drogas são cruciais para o sucesso da toxicologia forense. ${ }^{70-73}$

\section{EASI-MS}

Atualmente, a técnica EASI-MS vem sendo utilizada pelo Laboratório Thomson do Instituto de Química da Unicamp como uma técnica de screening para a identificação de várias classes de drogas de abuso. A maior parte da pesquisa é destinada à elucidação das novas drogas que estão sendo comercializadas, como é o caso de ecstasy, cocaína e LSD. Esses resultados são detalhados nos próximos itens.

\section{Ecstasy}

O composto 3,4-metilenodioximetanfetamina (MDMA), princípio ativo mais comumente encontrado na droga conhecida como ecstasy, é um derivado anfetamínico, classificado como droga alucinógica. O consumo de ecstasy tem aumentado entre os adolescentes e jovens adultos, ao longo dos últimos anos. $\mathrm{O}$ acesso cada vez mais amplo e a redução gradativa de preços favorecem a procura e o consumo desta droga de abuso. Muitos dos comprimidos vendidos com a designação de ecstasy contêm uma enorme variedade de drogas. Além do MDMA, outras anfetaminas e seus derivados são normalmente encontrados. Portanto, o termo ecstasy normalmente é usado para designar a forma de apresentação de como ela é vendida (comprimidos coloridos, com logotipos característicos), sendo sua real composição desconhecida. ${ }^{74-78}$

Atualmente, novas classes de drogas sintéticas, como derivados da piperazina, estão sendo introduzidas no mercado como alternativas aos compostos anfetamínicos e, dependendo do país, são vendidas livremente na internet na forma de pó, cápsulas ou comprimidos. Os derivados da piperazina incluem a benzilpiperazina (BZP), 1-(3,4-metilenodioxibenzil)piperazina (MDBP), triflúormetilfenilpiperazina (TFMPP), meta-clorofenilpiperazina ( $m$-CPP) e metoxifenilpiperazina (MeOPP) ${ }^{69}$ Estes compostos estão se espalhando cada vez mais pelo mundo, causando efeitos que ainda são muito pouco estudados.

A análise de triagem dos derivados anfetamínicos pode ser feitas por técnicas de imunoensaios (em matrizes biológicas) e/ou ensaios colorimétricos (em drogas brutas), que são muito úteis, mas que costumam apresentar tanto reações cruzadas como resultados falsos negativos e positivos, em diversas situações. Os métodos confirmatórios ou definitivos e, portanto, mais confiáveis e específicos para evidenciar a presença de compostos anfetamínicos são, geralmente, cromatográficos e/ou espectrofotométricos. No caso de testes colorimétricos como o reativo de Marquis, onde a adição de algumas gotas de formaldeído em meio ácido produz uma cor preta para resultados positivos na presença de MDMA, fornecem resultados negativos se apenas derivados da piperazina estiverem presentes no comprimido, onde nenhuma variação de cor será observada. ${ }^{79}$ Outras técnicas são usadas para identificação das piperazinas, como cromatografia gasosa acoplada com espectrômetro de massas (GC-MS), ${ }^{80}$ cromatografia líquida de alta eficiência acoplada com detector na região do ultravioleta (HPLC-UV) ${ }^{81}$ e LC-MS ${ }^{82}$ Entretanto, a grande maioria das metodologias analíticas é considerada complexa, por envolver preparação da amostra, ou pouco específica, como a TLC. Uma forma alternativa, rápida, confiável e reprodutível é a utilização da técnica EASI-MS.

Romão et al. ${ }^{83}$ mostraram que a técnica EASI-MS é capaz de detectar diversas drogas sintéticas diretamente sobre a superfície de comprimidos, sem a necessidade de preparação de amostra. O resultado é altamente específico e, em poucos segundos, indica a massa molar dos ingredientes ativos protonados, $[\mathrm{M}+\mathrm{H}]^{+}$. Fragmentações típicas e experimentos de MS/MS reforçam ainda mais o potencial de identificação da técnica. Entre as drogas de abuso estudadas pelo grupo de pesquisa, os derivados de piperazina, como $m$-CPP ${ }^{84} \mathrm{e}$ TFMPP, têm sido comumente identificados no mercado de drogas sintéticas do ecstasy, especialmente em amostras apreendidas pela Polícia Civil do Estado do Rio de Janeiro (PCERJ) e identificadas por GC-MS pelo Instituto de Criminalística Carlos Éboli (ICCE-RJ), Figuras $6 \mathrm{Sa}-\mathrm{b}$, material suplementar. O perfil químico desses comprimidos é bastante diferente de um típico comprimido de ecstasy, Figura 6Sd, material suplementar, onde o ingrediente ativo é detectado como molécula protonada $\left([\mathrm{M}+\mathrm{H}]^{+}: \mathrm{m} / z 197\right.$ para $m-\mathrm{CPP}$ e $[\mathrm{M}+\mathrm{H}]^{+}$: $\mathrm{m} / \mathrm{z}, 231$ para o TFMPP). Como excipientes, uma grande quantidade de íons é observada apenas para o comprimido de $m$-CPP $(\mathrm{m} / z$ de 300-900), Figura 6Sa, material suplementar.

Uma outra droga sintética que também vem sendo identificada pelo ICCE-RJ em comprimidos de ecstasy apreendidos pela PCERJ é a anfepramona $\left([\mathrm{M}+\mathrm{H}]^{+}: m / z 206\right.$ e $[2 \mathrm{M}+\mathrm{Cl}+2 \mathrm{H}]^{+}: m / z$ 447) ou dietilpropiona, Figura $6 \mathrm{Sc}$, material suplementar. Esse derivado de anfetamina tem ação anorexígena e possui uma menor potência estimulante em relação à anfetamina propriamente dita. Atualmente, ela se encontra na lista de substâncias psicotrópicas anorexígenas que constam na Resolução RDC n. 58, de 03/01/2008, publicada pela Agência Nacional de Vigilância Sanitária. Porém, apesar de ser considerada droga pela legislação sanitária em vigor, esta substância não se encontra proscrita no Brasil, podendo ser utilizada como medicamento. ${ }^{69}$

Um espectro de EASI-MS para o comprimido de ecstasy é mostrado na Figura 6Sd, material suplementar, contendo o princípio ativo MDMA, identificado como molécula protonada, $\left([\mathrm{M}+\mathrm{H}]^{+}: \mathrm{m} / z\right.$, 194), juntamente com seus fragmentos característicos $(\mathrm{m} / \mathrm{z}, 163,135$ e 105). 
A lactose também foi identificada e atua como diluente no comprimido, um excipiente cuja finalidade é aumentar a massa do mesmo. O íon de $m / z, 423$ corresponde a um sal protonado de cloridrato de MDMA formado por duas moléculas de MDMA e uma de ácido clorídrico [2MDMA $+\mathrm{Cl}+2 \mathrm{H}]^{+}$, podendo servir também como um "marcador químico" na identificação do MDMA e de seu processo de síntese, desde que o $\mathrm{HCl}$ seja utilizado na etapa de purificação. ${ }^{83}$

\section{$L S D$}

Outra droga de abuso, frequentemente apreendida pelo Departamento de Polícia Federal (DPF) do Brasil, é a dietilamida do ácido lisérgico (LSD), substância semissintética, produzida a partir do ácido lisérgico (um alcaloide produzido pelo Claviceps purpurea). O LSD é vendido ilegalmente na forma de selos (blotter papers), que possuem diferentes impressões. A própria forma de apresentação do LSD acaba sendo conveniente para a implementação de análises através da EASI-MS, uma vez que o ingrediente ativo adsorvido no papel é facilmente encontrado nas análises na forma de molécula protonada, $\operatorname{LSD}\left([\mathrm{M}+\mathrm{H}]^{+}: m / z\right.$ 324, Figura 7Sa, material suplementar).

Recentemente, selos apreendidos pelo DPF e pela PCERJ e analisadas no Instituto Nacional de Criminalística (INC-DF) e no ICCERJ, respectivamente, indicaram a presença de um novo composto, com estrutura bastante similar ao LSD, o 9,10-di-hidro-LSD. Essa nova droga ainda não se encontra na lista de substâncias piscotrópicas controladas e sua presença em selos apreendidos, ao invés da substância LSD, pode levar a resultados falsos positivos quando analisados por laboratórios forenses no Brasil, especialmente quando métodos com baixa especificidade são utilizados (testes de cor ou TLC). Aplicando o spray supersônico do EASI-MS, o 9,10-di-hidro-LSD é facilmente identificado como molécula protonada, $[\mathrm{M}+\mathrm{H}]^{+}: m / z 326$ (Figura 7Sb, material suplementar). A confirmação estrutural do 9,10-di-hidroLSD é alcançada quando são utilizados experimentos de $\mathrm{MS}^{\mathrm{n}}$, analisadores de massas de altíssima resolução e exatidão (EASI-FT-ICR MS $)^{85}$ ou medidas de ressonância magnética nuclear. Sete resultados positivos foram observados para a presença do 9,10-di-hidro-LSD em 30 selos aprendidos e analisados pelo INC-DPF e ICCE-RJ em colaboração com o Laboratório Thomson. ${ }^{85}$

\section{Cocaína}

A cocaína é um alcaloide encontrado nas folhas do vegetal Erytroxylum coca Lam, um arbusto ramificado originário da zona tropical dos Andes. Ilegal em vários países do mundo, a cocaína pode ser comercializada, principalmente por duas formas: a) de cloridrato; ou b) de base livre (pasta base, cocaína base livre, merla, free-base e crack). A principal diferença entre as formas está na via de administração: o cloridrato, um pó branco e cristalino, adminstrado por via intravenosa e intranasal, e a base livre, que é fumada, administrada via intrapulmonar, por apresentar baixo ponto de fusão e volatilizar-se em torno de 95 ${ }^{\circ} \mathrm{C}$. Com um custo menor do que a cocaína na forma de cloridrato, a "pedra" de cocaína base livre (crack) é hoje uma das drogas em grande expansão no mercado ilícito, principalmente entre os indivíduos de classes populacionais de menor poder aquisitivo, mas expandindo-se para outras populações. ${ }^{69} \mathrm{Na}$ cocaína, é comum encontrar algumas impurezas do processo de extração e refino e de adulterantes químicos, adicionados com o objetivo de imitar a ação farmacológica da droga e enganar o usuário. Usando a técnica EASI-MS para o screening de algumas amostras apreendidas pela PCERJ, além do princípio ativo ser facilmente detectado, vários adulterantes também foram identificados, Figura 8S, material suplementar. Lidocaína, benzocaína (ambos anestésicos) e cafeína (estimulante) são alguns exemplos de adulterantes. Em alguns casos, a cetamina é também detectada. A presença da cocaína na sociedade é de tal magnitude, que é comum encontrar a droga até na superfície do papel-moeda. ${ }^{63}$

\section{TLC/EASI-MS}

A técnica EASI-MS também permite acoplar em seu sistema de ionização métodos de separação como a TLC, uma técnica de baixo custo e de grande versatilidade, gerando o sistema chamado TLC/ EASI-MS. ${ }^{86,87}$

Em 2010, Sabino et al. ${ }^{88}$ analisaram vários padrões (MDMA, MDA, metilenodioxianfetamina, MDEA, 3,4-metilenodioxietilanfetamina, cafeína, cetamina, metanfetamina e anfetamina) e compararam as suas distâncias de retenção com amostras "reais" de ecstasy apreendidas pela PCERJ. Usando o sistema TLC/EASI-MS, após a otimização do sistema cromatográfico, foi possível analisar os spots, confirmando assim o ingrediente ativo presente na amostra analisada. Dessa forma, resultados falso-negativos podem ser totalmente excluídos. Usando como sistema eluente $\mathrm{CH}_{3} \mathrm{OH} / \mathrm{NH}_{4} \mathrm{OH}(98 / 2$ v \%), é possível obter valores de fatores de retenção (Rfs) diferentes para a maioria dos padrões analisados, Figura 9S, material suplementar, com exceção do MDMA (principal princípio ativo encontrado nos comprimidos de ecstasy) e da metanfetamina.

As Figuras 10Sa-g, material suplementar, mostram os espectros de EASI(+)-MS dos spots correspondentes aos padrões revelados no sistema $\mathrm{NH}_{4} \mathrm{OH}: \mathrm{CH}_{3} \mathrm{OH}(98 / 2 \mathrm{v} \%)$, que são detectados nas seguintes formas: MDEA (como molécula protonada $\left([\mathrm{M}+\mathrm{H}]^{+}: m / z\right.$, 208) e aduto de sódio, $\left.\left([\mathrm{M}+\mathrm{Na}]^{+}: m / z, 230\right)\right), 10 \mathrm{Sa}$; MDA $\left([\mathrm{M}+\mathrm{H}]^{+}\right.$: $m / z, 180) 10 \mathrm{Sb}$; MDMA ([M+H]+: $m / z, 194)$ e $m / z, 163$ e 135) $10 \mathrm{Sc}$; metanfetamina $(\mathrm{M}+\mathrm{H}]^{+}: \mathrm{m} / \mathrm{z}, 150$ e $\mathrm{m} / \mathrm{z}$ 91) correspondente ao íon tropílio, 10Sd; anfetamina $(\mathrm{M}+\mathrm{H}]^{+}: \mathrm{m} / z$ 136) 10Se; cetamina (M $+\mathrm{H}]^{+}: m / z$ 237), 10Sf; e cafeína $(\mathrm{M}+\mathrm{H}]^{+}: m / z$ 195) 10Sg. Para as amostras reais, os autores observaram, em sua maioria, resultados positivos para a molécula de MDMA $(\mathrm{m} / \mathrm{z}, 194 \mathrm{e} \mathrm{m} / \mathrm{z}$ 423). Nos casos em que os resultados foram negativos para o TLC (amostras T 6, T 18 e T 19), foram verificados resultados positivos para cafeína (T 6 ) e lidocaína (T 18 e T 19). ${ }^{88}$

\section{CONCLUSÃO}

Nesta revisão, foram discutidas as principais metodologias que têm sido desenvolvidas para solucionar problemas no campo da criminalística ou da química forense, enfatizando suas respectivas particularidades. A espectrometria de massas com técnicas de dessorção/ionização à pressão ambiente vem proporcionando grandes avanços nos estudos de falsificação de documentos. Análises de idade relativa e datação de tintas, cruzamentos de traços e falsificação em documentos, praticados principalmente pelo uso de canetas esferográficas, são realizadas de maneira rápida (em segundos) e não destrutiva, usando técnicas como a EASI-MS. Esta técnica vem se mostrando mais eficiente do que as metodologias desenvolvidas por espectroscopia no infravermelho médio e Raman, por conseguir detectar variações na composição das tintas devido ao envelhecimento (natural ou acelerado em condições controladas).

Atualmente, as análises de GSR orgânicos provenientes de disparos de armas de fogo vêm ganhando importância na área de balística forense, devido ao surgimento das munições ambientais (sem metais pesados). Várias metodologias têm sido desenvolvidas usando principalmente cromatografia líquida ou eletroforese capilar. Entre elas, a cromatografia líquida proporciona uma maior especificidade e sensibilidade, já que os GSR se decompõem ao longo do tempo, inviabilizando o uso da eletroforese capilar na análise de amostras envolvendo casos reais. Entretanto, levando em consideração que existem vários casos de homicídios que acontecem diariamente envolvendo armas de fogo, e que ambas as técnicas requerem procedimentos de preparação da amostra, torna-se inviável a aplicação 
destas técnicas em análises de rotina. Porém, estudos de recentidade de disparos de armas de fogo poderiam ser realizados usando este tipo de metodologia. Em geral, a fluorescência de raios-X vem se mostrando uma técnica com potencial para análise de GSR em locais de crime. Características como conservação da amostra, velocidade de análise, multielementariedade e preço acessível tornam a detecção de GSR inorgânicos usando XRF uma técnica promissora. Acoplada a sistemas óticos, seria possível ainda testar essa técnica na obtenção de informações complementares como, por exemplo, associar a quantidade de resíduos gerados com a distância entre o alvo e o atirador.

$\mathrm{Na}$ investigação de drogas de abuso, alternativas criadas usando técnicas de ionização em condições ambiente, como a EASI-MS, minimizam a etapa de preparação de amostras, podendo ser aplicadas para identificações definitivas com grande rapidez de resposta e para obtenção de perfis químicos de drogas de abuso, podendo ser implementadas em laboratórios forenses.

\section{MATERIAL SUPLEMENTAR}

O material suplementar (Figuras 1S a 10S) está disponível gratuitamente em http://quimicanova.sbq.org.br, na forma de arquivo PDF.

\section{AGRADECIMENTOS}

À CAPES e à FAPESP por uma bolsa para W. Romão.

\section{REFERÊNCIAS}

1. Causin, V.; Casamassima, R.; Marega, C.; Maida, P.; Schiavone, S.; Marigo, A.; Villari, A.; J. Forensic Sci. 2008, 53, 1468.

2. Bojko, K.; Roux, C.; Reedy, B. J.; J. Forensic Sci. 2008, 53, 1458.

3. Egan, W. J.; Morgan, S. L.; Bartick, E. G.; Merrill, R. A.; Taylor, H. J.; Anal. Bioanal. Chem. 2003, 376, 1279.

4. Merrill, R. A.; Bartick, E. G.; Taylor, J. H.; Anal. Bioanal. Chem. 2003, 376, 1272

5. Claybourn, M.; Ansell, M.; Sci Just. 2000, 40, 261.

6. Geiman, I.; Leona, M.; Lombardi, J. R.; J. Forensic Sci. 2009, 54, 947.

7. Adam, C. D.; Forensic Sci. Int. 2008, 182, 27.

8. Brazeau, L.; Chem, C.; Gaudreau, M.; J. Forensic Sci. 2007, 52, 209.

9. Egan, W. J.; Galipo, R. C.; Kochanowski, B. K.; Morgan, S. L.; Bartick, E. G.; Miller, M. L.; Ward, D. C.; Mothershead, R. F.; Anal. Bioanal. Chem. 2003, 376, 1286.

10. Bugler, J. H.; Buchner, H.; Dallmayer, A.; J. Forensic Sci. 2008, 53, 982.

11. Morales, E. B.; Vazquez, A. L. R.; J. Chromatogr., A 2004, 1061, 225.

12. Vogt, C.; Vogt, J.; Becker, A.; Rohde, E.; J. Chromatogr. 1997, 781, 391.

13. Cruces-Blanco, C.; Gámiz-Gracia, L.; García-Campnã, A. M.; Trends Anal. Chem. 2007, 26, 215.

14. Assuncao, N. A.; Bechara, E. J. H.; Simionato, A. V. C.; Tavares, M. F. M.; Carrilho, E.; Quim. Nova 2008, 31, 2124.

15. Jager, A. V.; da Silva, C. L.; Moraes, E. P.; Pereira, E. A.; de Lima, E. C.; Fonseca, F. N.; Tonin, F. G.; Micke, G. A.; Santos, M. R.; de Oliveria, M. A. L.; de Moraes, M. D. L.; van Kampen, M. H.; Fujiya, N. M.; J. Braz. Chem. Soc. 2003, 14, 281.

16. Weyermann, C.; Kirsch, D.; Costa-Vera, C.; Spengler, B.; J. Am. Soc. Mass Spectrom. 2006, 17, 297.

17. Lalli, P. M.; Sanvido, G. B.; Garcia, J. S.; Haddad, R.; Cosso, R. G.; Maia, D. R. J.; Zacca, J. J.; Maldaner, A. O.; Eberlin, M. N.; Analyst 2010, 135, 745 .

18. Siegel, J.; Allison, J.; Mohr, D.; Dunn, J.; Talanta 2005, 67, 425.

19. Jones, R. W.; Cody, R. B.; McClealland, J. F.; J. Forensic Sci. 2006, 51, 915.

20. Ifa, D. R.; Gumaelius, L. M.; Eberlin, L. S.; Manicke, N. E.; Cooks R. G.; Analyst 2007, 132, 461.
21. Maind, S. D.; Kumar, S. A.; Chattopadhyay, N.; Gandhi, Ch.; Sudersanan, M.; Forensic Sci. Int. 2006, 159, 32.

22. Zavattaro, D.; Quarta, G.; Elia, M. D.; Calcagnile, L.; Forensic Sci. Int. 2007, 167, 160.

23. Coumbaros, J.; Kirkbride, K. P.; Klass, G.; Skinner, W.; Forensic Sci. Int. 2009, 193, 42.

24. Donnelly, S.; Marrero, J. E.; Cornell, T.; Fowler, K.; Allison, J.; J. Forensic Sci. 2010, 55, 129.

25. Zeichner, A.; Anal. Bioanal. Chem. 2003, 376, 1178.

26. Oommen, Z.; Pierce, S. M.; J. Forensic Sci. 2006, 51, 509.

27. Romolo, F. S.; Margot, P.; Forensic Sci. Int. 2001, 119, 195.

28. Berk, R. E.; J. Forensic Sci. 2009, 54, 69.

29. Berk, R. E.; J. Forensic Sci. 2009, 54, 60

30. Niewoehner, L.; Andrasko, J.; Biegstraaten, J.; Gunaratnam, L.; Steffen, S.; Uhlig, S.; Antoni, S.; J. Forensic Sci. 2008, 53, 162.

31. Martiny, A.; Campos, A.P.C.; Sader, M.S.; Pinto, A. L.; Forensic Sci. Int. 2008, 177, 9 .

32. Silva, M. J.; Cortez, J.; Pasquini, C.; Honorato, R. S.; Paim, A. P. S.; Pimentel, M. F.; J. Braz. Chem. Soc. 2009, 20, 1887.

33. Tagliaro, F.; Bortolotti, F.; Electrophoresis 2006, 27, 231.

34. Perret, D.; Marchse, S.; Gentili, A.; Curini, R.; Terracciano, A.; Bafile, E.; Romolo, F.; Chromatographia 2008, 68, 1612.

35. Berendes, A.; Neimke, D.; Schumacher, R.; Barth, M.; J. Forensic Sci. 2006, 51, 1085.

36. Takahashi, M.; Kinoshita, H.; Nishiguchi, M.; Nishio, H.; Legal Med. 2010, 12, 102 .

37. Schweitzer, J. S.; Trombka, J. I.; Floyd, S.; Selavka, C.; Zeosky, G.; Gahn, N.; McClanahan, T.; Burbine, T.; Nucl. Instrum. Methods Phys. Res., Sect. B 2005, 241, 816.

38. Sarkis, J. E. S.; Neto, O. N.; Viebig, S.; Durrant, S. F.; Forensic Sci. Int. 2007, 172, 63 .

39. dos Reis, E. L. T.; Sarkis, J. E. S.; Rodrigues, C.; Negrini Neto, O.; Viebig, S.; Quim. Nova 2004, 27, 409.

40. Coumbaros, J.; Kirkbride, K. P.; Klass, G.; Skinner, W.; Forensic Sci. Int. 2001, 119, 72.

41. Gagliano-Candela, R.; Colucci, A. P.; Napoli, S.; J. Forensic Sci. 2008 $53,321$.

42. Shibuya, E. K.; Sarkis, J. E. S.; Negrini-Neto, O.; Ometto, J. P. H. B.; J. Braz. Chem. Soc. 2007, 18, 205.

43. Mendes, L. B.; Documentoscopia, $3^{\text {a }}$ ed., Millennium: Campinas, 2010.

44. Geladi, P.; Kowalski, B. R.; Anal. Chim. Acta 1986, 185, 1.

45. Koenig, J. L.; Wang, S-Q.; Bahargava, R.; Anal. Chem. 2001, 73, 360.

46. Carneiro, R. L.; Braga, J. W. B.; Poppi, R. J.; Tauler, R.; Analyst 2008, 133,774 .

47. Holler, F. J.; Skoog, D. A.; Crouch, S. R.; Princípios de Análise Instrumental, $6^{\mathrm{a}}$ ed., Artmed S.A.: Porto Alegre, 2009.

48. Romão, W.; Franco, M. F.; Iglesias, A. H.; Sanvido, G. B.; Maretto, D. A.; Gozzo, F. C.; Poppi, R. J.; Eberlin, M. N.; De Paoli, M.-A.; Polym. Degrad. Stab. 2010, 95, 666.

49. Romão, W.; Franco, M. F.; Corilo, Y. E.; Eberlin, M. N.; Spinacé, M. A. S.; De Paoli, M-A.; Polym. Degrad. Stab. 2009, 94, 1849.

50. Hirabayashi, A.; Sakairi, M.; Koizumi, H.; Anal. Chem. 1994, 66, 4557.

51. Hirabayashi, A.; Sakairi, M.; Koizumi, H.; Anal.Chem. 1995, 67, 2878.

52. Hirabayashi, A.; Hirabayashi, Y.; Sakairi, M.; Koizumi, H.; Rapid Commun. Mass Spectrom. 1996, 10, 1703.

53. Haddad, R.; Sparrapan, R.; Eberlin, M. N.; Rapid Commun. Mass Spectrom. 2006, 20, 2901.

54. Haddad, R.; Sparrapan, R.; Kotiaho, T.; Eberlin, M. N.; Anal. Chem. 2008, 80,898 .

55. Alberici, R. M.; Simas, R. C.; Sanvido, G. B.; Romão, W.; Lalli, P. M.; Benassi, M.; Cunha, I. B. S.; Eberlin, M. N.; Anal. Bioanal. Chem. 2010, 398, 265. 
56. Haddad, R.; Catharino, R. R.; Marques, L. A.; Eberlin, M. N.; Rapid Commun. Mass Spectrom. 2008, 22, 3662.

57. Saraiva, A. S.; Abdelnur, P. V.; Catharino, R. R.; Nunes, G.; Eberlin, M. N.; Rapid Commun. Mass Spectrom. 2009, 23, 357.

58. Simas, R. C.; Catharino, R. R.; Cunha, I. B. S.; Cabral, E. C.; BarreraArellano, D.; Eberlin, M. N.; Alberici, R. M.; Analyst 2010, 135, 738.

59. Abdelnur, P. V.; Eberlin, L. S.; de Sá, G. F.; Souza, V.; Eberlin, M. N.; Anal. Chem. 2008, 80, 7882.

60. Sawaya, A. C. H. F.; Abdelnurb, P. V.; Eberlin, M. N.; Kumazawac, S.; Ahnd, M. R.; Bangd, K. S.; Nagarajae, N.; Bankovaf, V. S.; Afrouzang, H.; Talanta 2010, 81, 100.

61. Corilo, Y. E.; Vaz, B. G.; Simas, R. C.; Nascimento, H. D. L.; Klitzke, C. K.; Pereira, R. C. L.; Bastos, W. L.; Rodgers, R. P.; Eberlin, M. N.; Anal. Chem. 2010, 82, 3990.

62. Alberici, R. M.; Simas, R. C.; de Souza, V.; de Sá, G. F.; Daroda, R. J.; Eberlin, M. N.; Anal. Chim. Acta 2010, 659, 15.

63. Eberlin, L. S.; Haddad, R.; Neto, R. C. S.; Cosso, R. G.; Maia, D. R. J.; Maldaner, A. O.; Zacca, J. J.; Sanvido, G. B.; Romão, W.; Vaz, B. G.; Ifa, D. R.; Dill, A.; Cooks, R. G.; Eberlin, M. N.; Analyst 2010, 135, 2533.

64. Tocchetto, D.; Balística Forense: Aspectos técnicos e jurídicos, 5ª ed., Millennum: Campinas, 2009.

65. Wallace, J. S.; Chemical Analysis of Firearms, Ammunition and Gunshot residue, Taylor \& Francis Group: New York, 2008.

66. Romão, W.; Franco, M. F.; Bueno, M. I. M. S.; Eberlin, M. N.; De Paoli, M.-A.; J. Appl. Polym. Sci. 2010, 117, 2993.

67. Correa, D. N.; Romão, W.; Schwab, N. V.; Hamada, A. A.; Campos, C. C. J.; Plácido, G. P.; Menezes, M. R.; Razzo, D.; Sabino, B. D.; Martyni, A.; Campos, A.; Bueno, M. I. M. S.; Eberlin, M. N.; $33^{a}$ Reunião Anual da Sociedade Brasileira de Química, Águas de Lindóia, Brasil, 2010.

68. Yinon, J.; Advances in forensic applications of mass spectrometry, CRC, Press: Boca Raton, 2004.

69. Passagli, M.; Toxicologia Forense, $2^{\mathrm{a}}$ ed., Millennum: Campinas, 2009.

70. Bouzas, N. F.; Dresen, S.; Munz, B.; Weinmann, W.; Anal. Bioanal. Chem. 2009, 395, 2499.
71. Ortiz, R. S.; Antunes, M. V.; Linden, R.; Quim. Nova 2010, 33, 389.

72. da Costa, J. L.; Pintao, E. R.; Corrigliano, C. M. C.; Negrini Neto, O.; Quim. Nova 2009, 32, 965.

73. Jenkins, K. M.; Young, M. S.; Mallet, C. R.; Elian, A. A.; J. Anal. Toxicol. 2004, 28, 50 .

74. Schawartz, S. H.; Miller, N. S.; Pediatrics 1997, 100, 705.

75. Morton, J.; Pharmacology 2005, 5, 79.

76. Kalant, H.; Can. Med. Assoc. J. 2001, 165, 917.

77. Gowing, L. R.; Henry-Edwards, S. M.; Irvini, R. J.; Ali, R. L.; Drug Alcohol Rev. 2002, 21, 53.

78. Morgan, M. J.; Psychopharmacology 2000, 230.

79. Jeffrey, W.; Colour tests; Analysis of Drugs and Poisons in Pharmaceuticals, Body Fluids and Postmortem Material, Wiley: London, 2004.

80. Caccia, S.; Ballabio, M.; Fanelli, R.; Guiso, G.; Zanini, M. G.; J. Chromatogr. 1981, 210, 311.

81. Miller, R. L.; Devane, C. L.; J. Chromatogr. 1986, 374, 388.

82. Patel, B. N.; Sharma, N.; Sanyal, M.; Shrivastav, P. S.; J. Chromatogr., B: Anal. Technol. Biomed. Life Sci. 2008, 871, 44.

83. Romão, W.; Lalli, P. M.; Franco, M. F.; Sanvido, G.; Schwab, N. V.; Lanaro, R.; Costa, J. L.; Sabino, B. D.; Bueno, M. I. M. S.; Sa, G. F.; Daroda, R. J.; Souza, V.; Eberlin, M. N. Anal. Bioanal. Chem. (2010), doi: 10.1007/s00216-011-4883-9.

84. Lanaro, R.; Costa, J. L.; Zanolli Filho, L. A.; Cazenave, S. O. S.; Quim. Nova 2010, 33, 725.

85. Romão, W.; Sabino, B. D.; Júnior, A. C.; Correa, D. N.; Vaz, B. G.; Eberlin, M. N.; 58 ASMS Conference on Mass Spectrometry and Allied Topics, Salt Lake City, USA, 2010.

86. Kato, N.; Pharm, B.; Fujita, S.; Pharm, B.; Ohta, H.; Fukuba, M.; Pharm, M.; Toriba, A.; Hayakawa, K.; J. Forensic Sci. 2008, 53, 1367.

87. Zakrzewska, A.; Parczewski, A.; Kazmierczak, D.; Ciesielski, W.; Kochanaa, J.; Acta Chim. Slov. 2007, 54, 106

88. Sabino, B. D.; Sodré, M. L.; Alves, E. A.; Rozembaum, H. F.; Alonso, F. O. M.; Correa, D. N.; Eberlin, M. N.; Romão, W.; Brazilian J. Anal. Chem. 2010, 1, 6 . 
Wanderson Romão, Nicolas V. Schwab e Maria Izabel M. S. Bueno*

Departamento de Química Analítica, Instituto de Química, Universidade Estadual de Campinas, CP 6154, 13083-970 Campinas - SP, Brasil

Regina Sparrapan e Marcos N. Eberlin

Departamento de Química Orgânica, Instituto de Química, Universidade Estadual de Campinas,

CP 6154, 13083-970 Campinas - SP, Brasil

Andrea Martiny

Instituto Nacional de Metrologia, Normalização e Qualidade Industrial, Av. N. Sra. das Graças, 50,

25250-020 Duque de Caxias - RJ, Brasil

Bruno D. Sabino

Instituto Nacional de Metrologia, Normalização e Qualidade Industrial, Av. N. Sra. das Graças, 50,

25250-020 Duque de Caxias - RJ / Instituto de Criminalística Carlos Éboli, R. Pedro I, 28, 20060-050 Rio de Janeiro - RJ, Brasil

Adriano O. Maldaner

Polícia Federal Brasileira, Ministério da Justiça, Instituto Nacional de Criminalística, 70610-200 Brasília - DF, Brasil

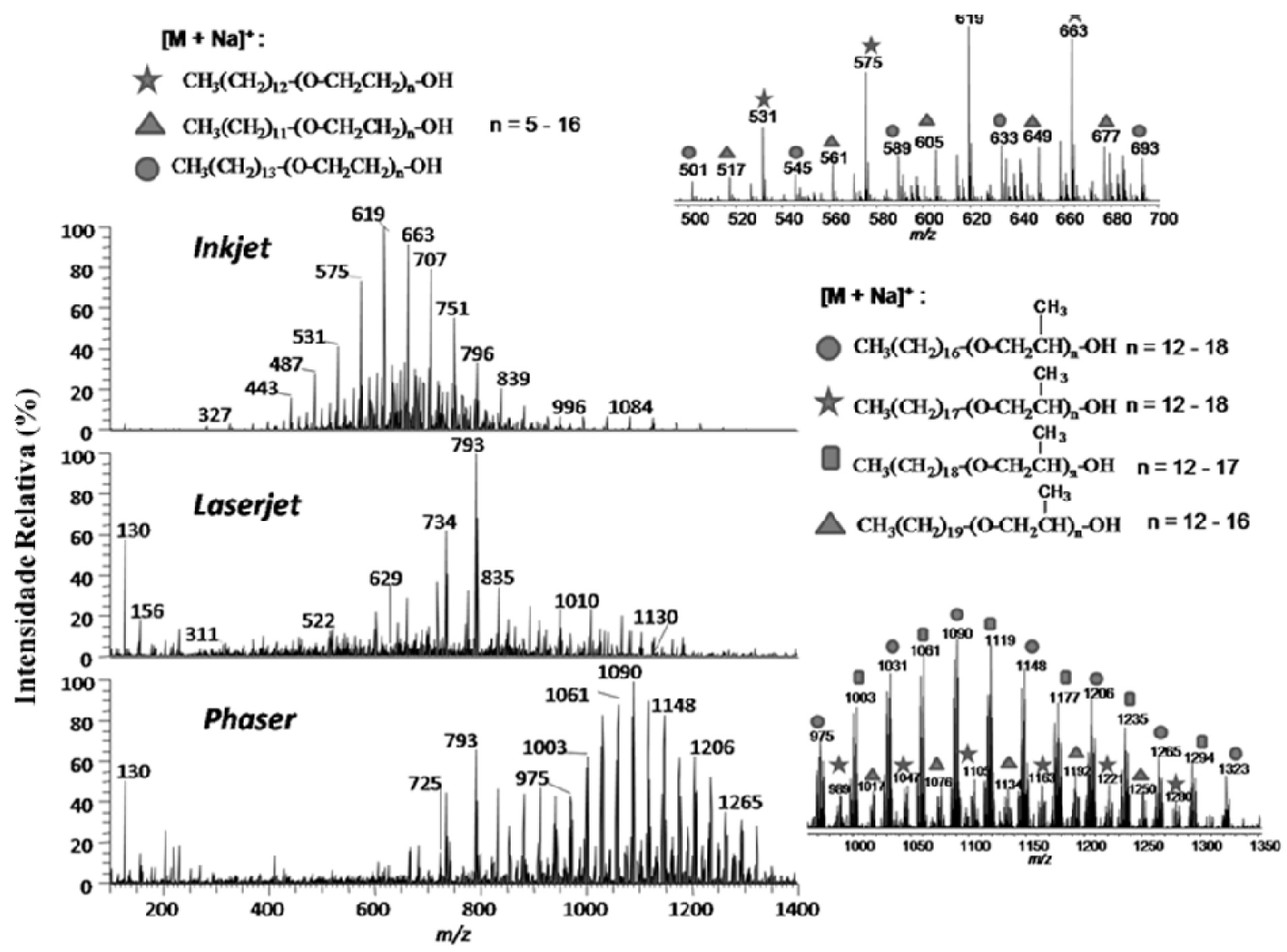

Figura 1S. Perfis químicos obtidos usando EASI(+)-MS para as notas falsas produzidas no Laboratório Thomson usando as impressoras: (a) inkjet; (b) laserjet e (c) phaser. Adaptada da ref. 63

*e-mail: bell@iqm.unicamp.br 


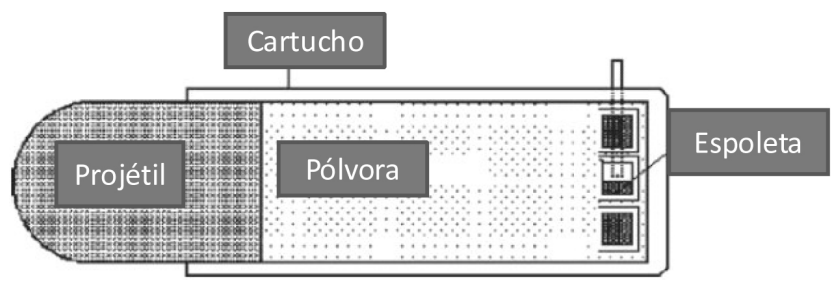

Figura 2S. Esquema de um cartucho para arma de fogo de alma raiada. Adaptada da ref. 65
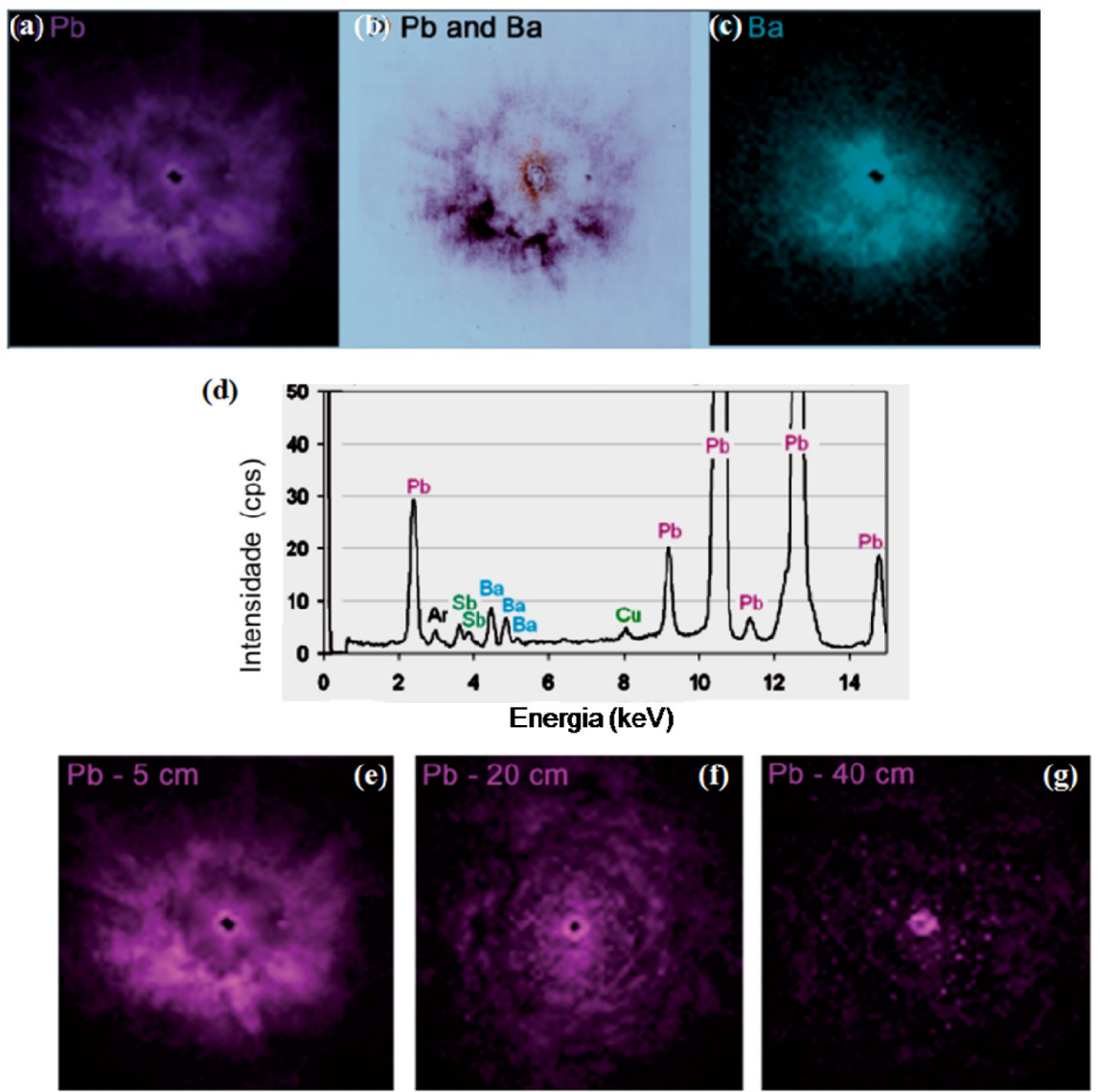

Figura 3S. (a) Análises de XRF para a obtenção de imagens de $\mathrm{Pb}$ (a) e Ba (c). Imagem de resíduos revelados por testes colorimétricos usando rodizionato de sódio (b), onde a coloração roxa corresponde ao Pb e a vermelha ao Ba. Espectro de XRF de um ponto analisado para a identificação da composição total do GSR (d). Imagens elementares para o Pb em função da distância entre o alvo e a arma (e-g). Adaptada da ref. 35 

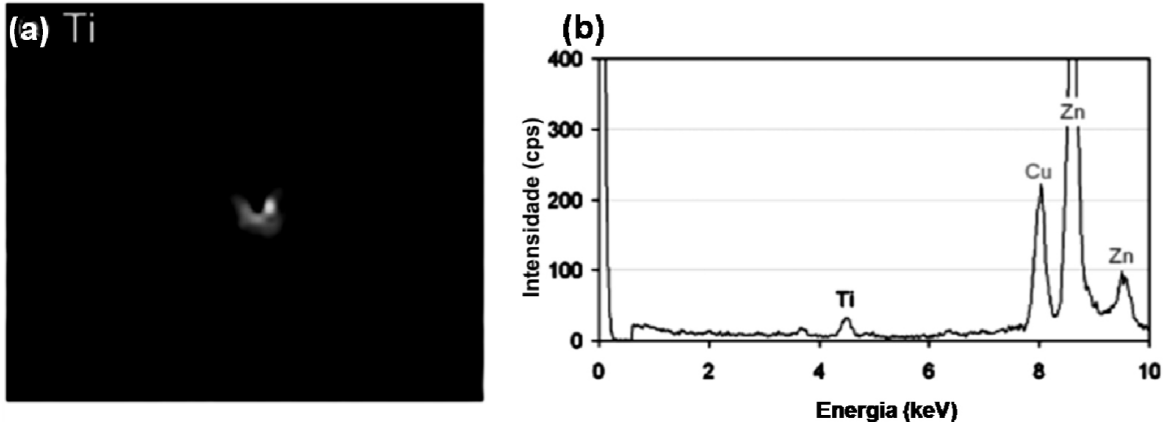

Figura 4S. Análises de XRF para a construção da imagem elementar para o elemento Ti, resíduo constituinte de algumas misturas iniciadoras de munições não tóxicas (a). Espectro de XRF de uma região do resíduo, para estimar a composição total (b). Adaptada da ref. 35
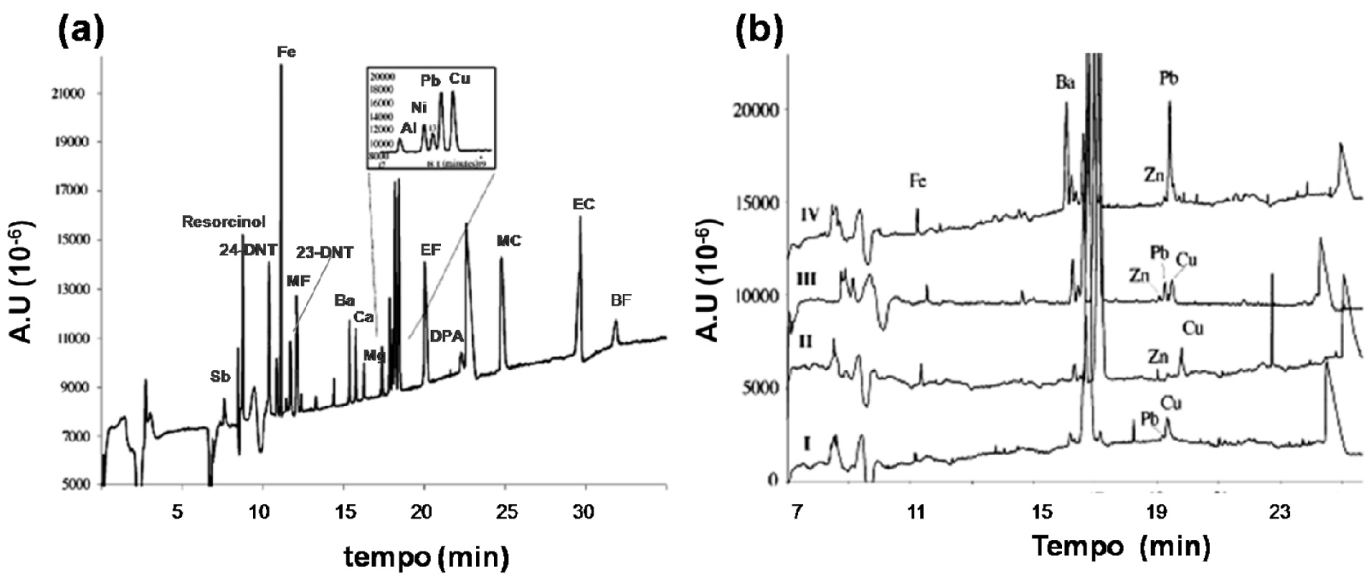

Figura 5S. (a) Separação simultânea de GSR orgânicos e inorgânicos sob condições ótimas, onde Sb = antimônio; 24-DNT=2,4-dinitrotolueno; Fe = ferro; 23DNT = 2,3-dinitrotolueno; $B a=$ Bário; $C a=$ cálcio; $M g=$ magnésio; $A l=$ alumínio $; \mathrm{Ni}=$ níquel; $P b=$ chumbo Cu = cobre; $M F=$ di-metilftalato; $M C=$ metil centralina; $E C=$ etil centralina; $E F=$ di-etilftalato; $D P A=$ difenilamina; $B F=$ di-butilftalato; $(b)$ eletroferogramas obtidos a partir de GSR em condições reais usando um revólver calibre .32: $I=$ branco; $I I=$ palma da mão; $I I I=$ GSR coletado após 1 disparo; $I V=$ GSR coletados após 3 disparos. Adaptada da ref. 11 

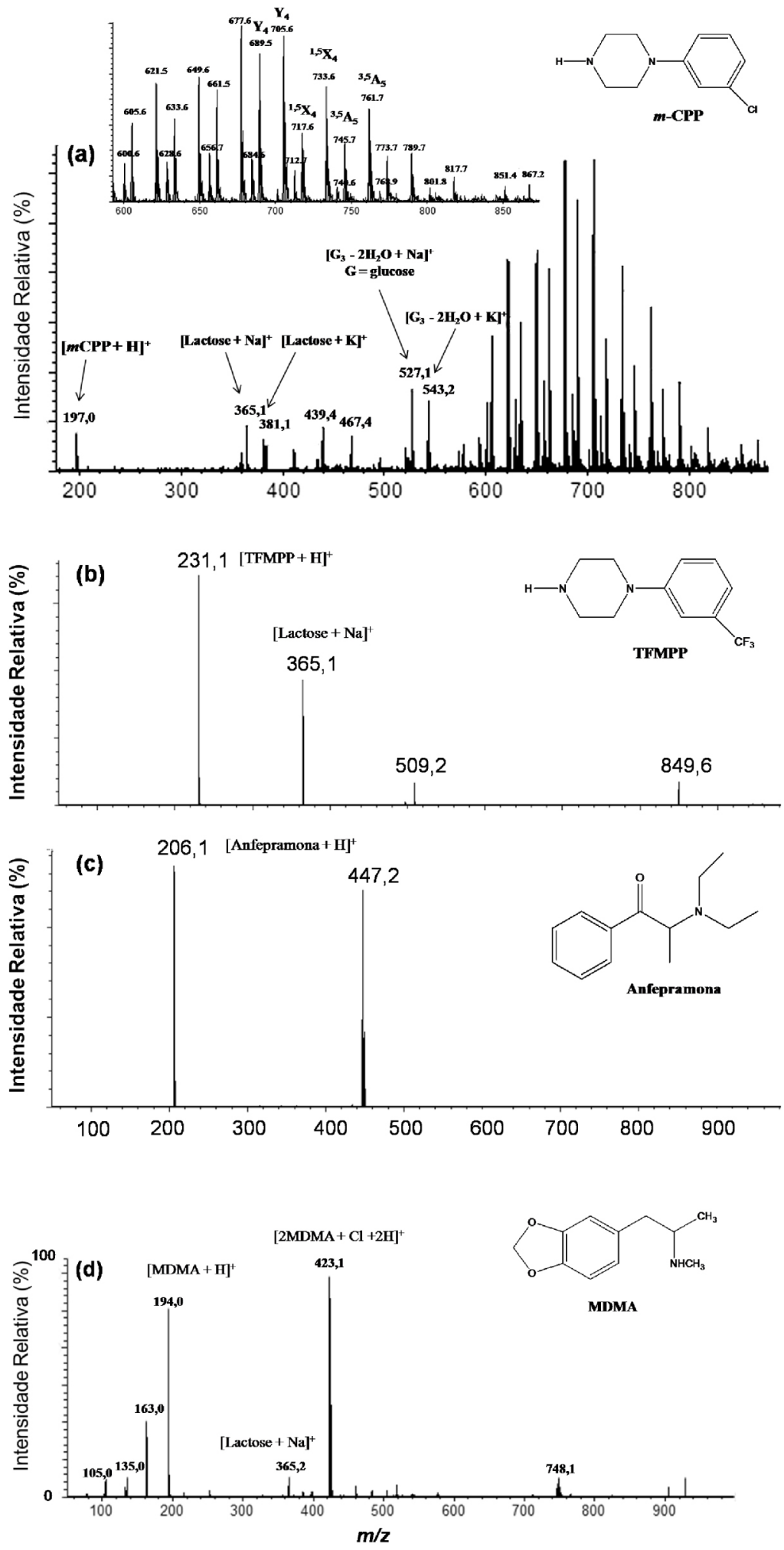

Figura 6S. EASI(+)-MS de comprimidos tipicamente vendidos como ecstasy: (a) m-CPP, (b) TFMPP, (c) Anfepramona e (d) MDMA. Adaptada da ref. 83 


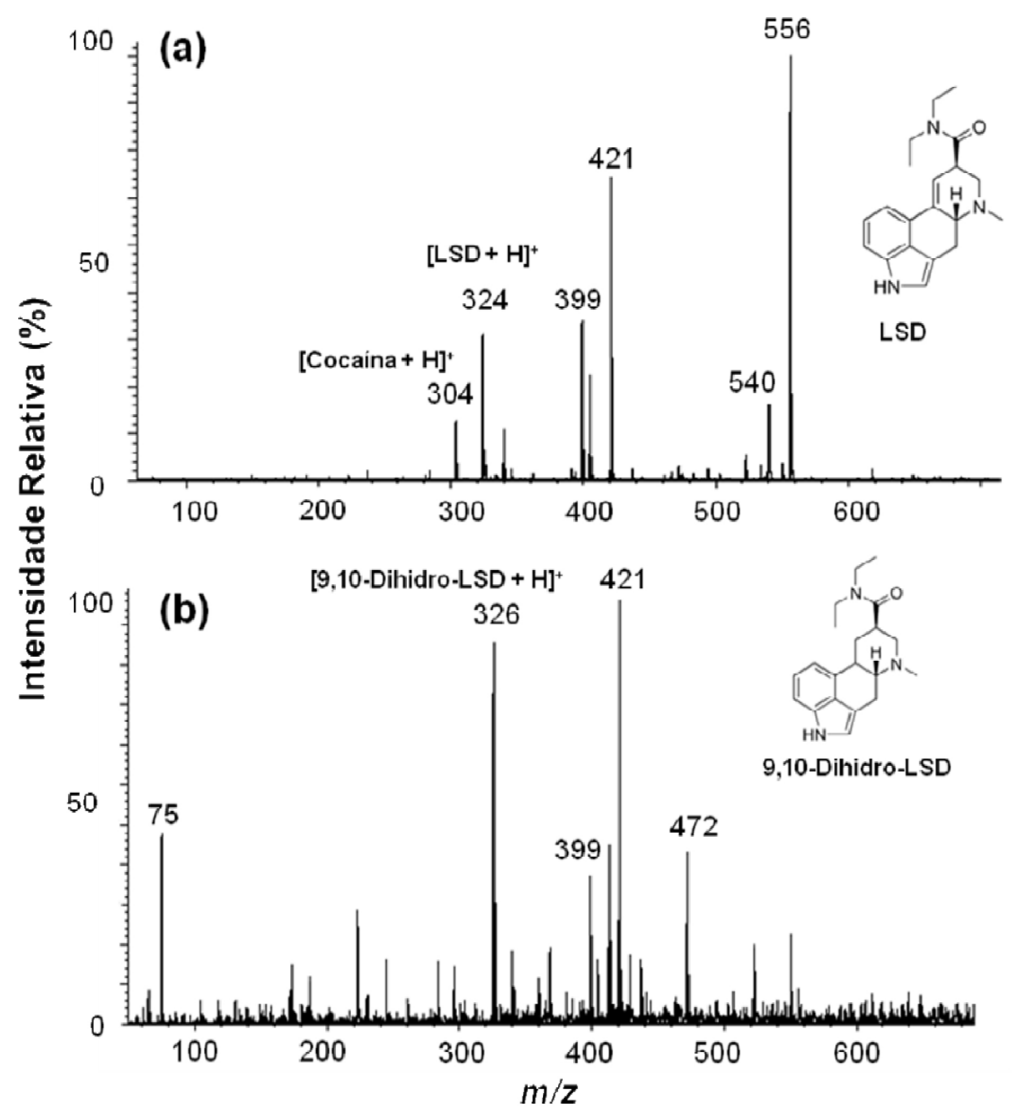

Figura 7S. EASI(+)-MS de amostras vendidas como LSD: (a) LSD e (b) 9,10-di-hidro-LSD. Adaptada da ref. 85

(a)

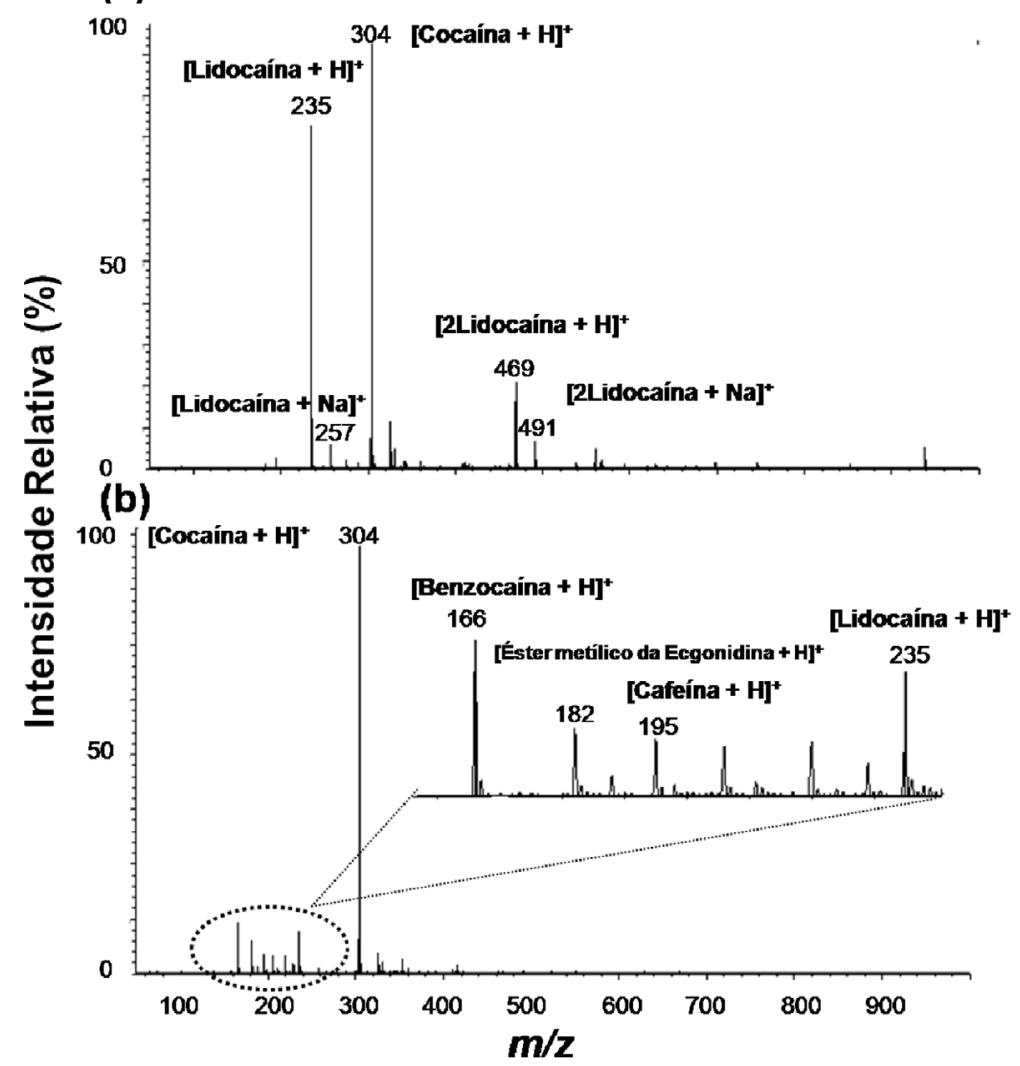

Figura 8S. EASI-MS para amostras de cocaína apreendidas pela Polícia Civil do Rio de Janeiro 

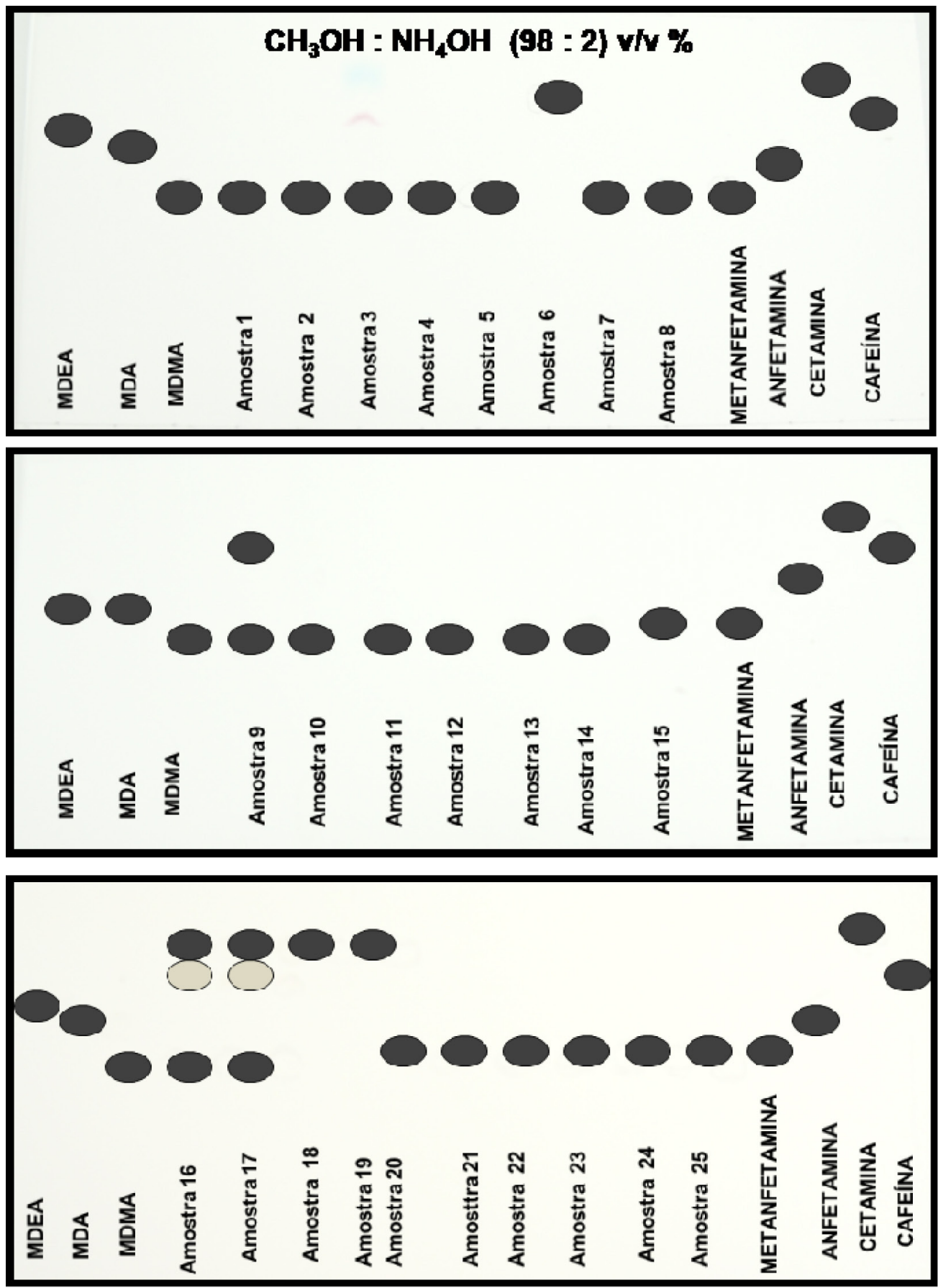

Figura 9S. TLC referentes a 7 padrões comumente testados e 25 comprimidos de ecstasy apreendidos pela PCERJ (T 1-T 25). Os spots foram revelados por radiação UV e são representadas por círculos pretos e cinzas (menos intensos). Adaptada da ref. 88 

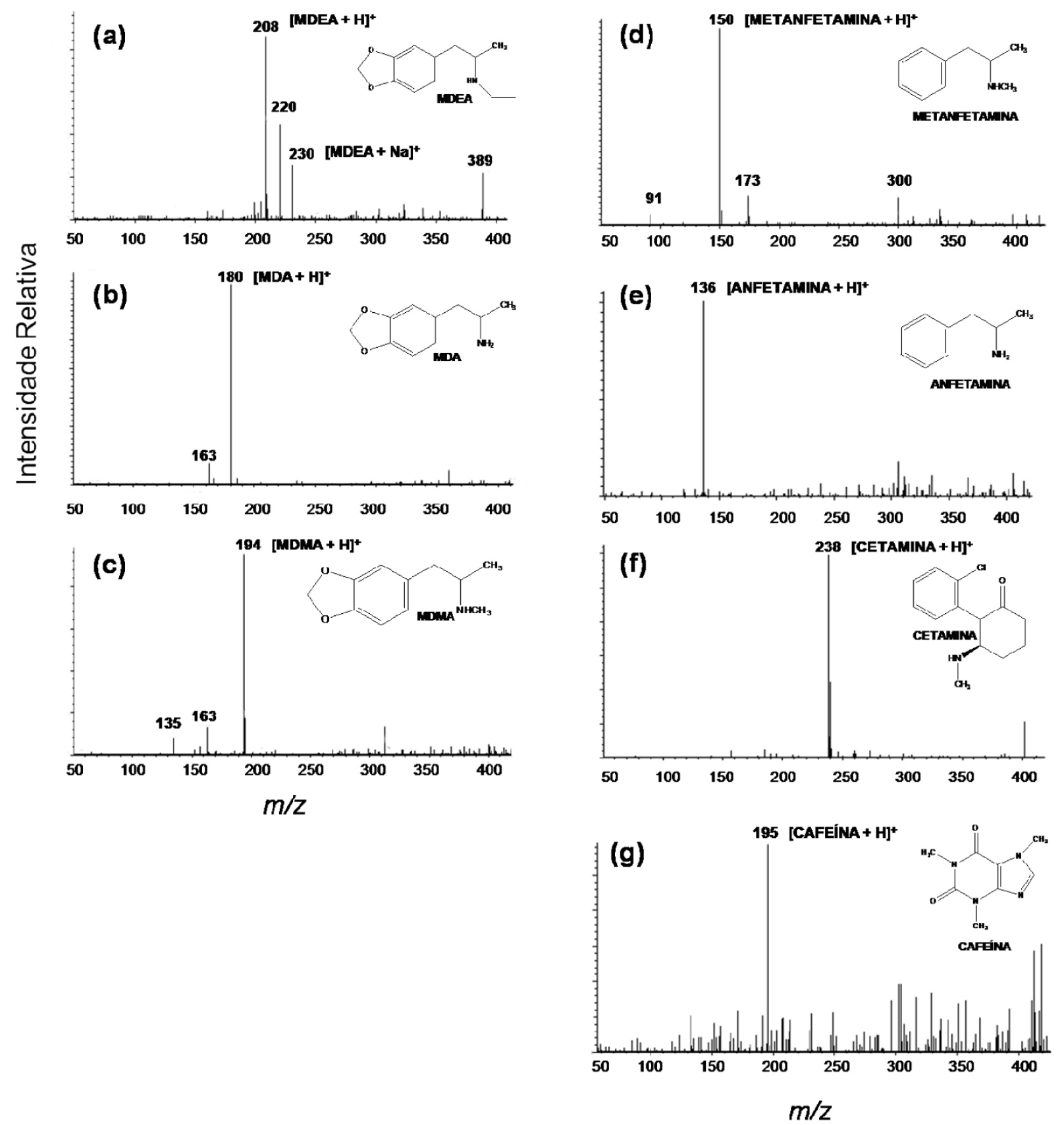

Figura 10S. EASI(+)-MS obtidos diretamente sob a superfície dos spots de TLC correspondendo aos sete padrões testados em análise de rotina: (a) MDEA, (b) MDA, (c) MDMA, (d) metanfetamina, (e) anfetamina, ( $f$ ) cetamina e $(g)$ cafeína. Adaptada da ref. 88 